NBER WORKING PAPER SERIES

\title{
ON THE CONSEQUENCES OF DEMOGRAPHIC CHANGE FOR RATES OF RETURNS TO CAPITAL, AND THE DISTRIBUTION OF WEALTH AND WELFARE
}

\author{
Dirk Krueger \\ Alexander Ludwig \\ Working Paper 12453 \\ http://www.nber.org/papers/w12453
NATIONAL BUREAU OF ECONOMIC RESEARCH 1050 Massachusetts Avenue
Cambridge, MA 02138
August 2006

We thank participants of seminars at the LSE, Ente Einaudi, Koc, MEA, the 2005 Cleveland FED International Macroeconomics conference, the 2006 Carnegie Rochester conference, the 2006 SED Meetings and the 12th Dubrovnik Economic Conference for many useful comments. We are especially indebted to our discussant Ayse Imrohoroglu for many helpful suggestions and comments. The authors can be reached at dirk.krueger@wiwi.uni-frankfurt.de and alexander.ludwig@ mea.uni-mannheim.de. This paper was prepared for the Spring 2006 Carnegie-Rochester Conference on Public Policy. The views expressed herein are those of the author(s) and do not necessarily reflect the views of the National Bureau of Economic Research.

(C2006 by Dirk Krueger and Alexander Ludwig. All rights reserved. Short sections of text, not to exceed two paragraphs, may be quoted without explicit permission provided that full credit, including $(\odot$ notice, is given to the source. 
On the Consequences of Demographic Change for Rates of Returns to Capital, and the Distribution of Wealth and Welfare

Dirk Krueger and Alexander Ludwig

NBER Working Paper No. 12453

August 2006

JEL No. C68, D33, E17, E25

\begin{abstract}
$\underline{\text { ABSTRACT }}$
This paper employs a multi-country large scale Overlapping Generations model with uninsurable labor productivity and mortality risk to quantify the impact of the demographic transition towards an older population in industrialized countries on world-wide rates of return, international capital flows and the distribution of wealth and welfare in the OECD. We find that for the U.S. as an open economy, rates of return are predicted to decline by 86 basis points between 2005 and 2080 and wages increase by about $4.1 \%$. If the U.S. were a closed economy, rates of return would decline and wages increase by less. This is due to the fact that other regions in the OECD will age even more rapidly; therefore the U.S. is "importing" the more severe demographic transition from the rest of the OECD in the form of larger factor price changes. In terms of welfare, our model suggests that young agents with little assets and currently low labor productivity gain, up to $1 \%$ in consumption, from higher wages associated with population aging. Older, asset-rich households tend to lose, because of the predicted decline in real returns to capital.
\end{abstract}

\author{
Dirk Krueger \\ Johann Wolfgang Goethe University Frankurt-am-Main \\ Mertonstrasse 17, PF 81 \\ 60054 Frankfurt-am-Main \\ GERMANY \\ and NBER \\ dirk.krueger@wiwi.uni-frankfurt.de
}

Alexander Ludwig

Mannheim Research Institute for the Economics of Aging, MEA

University of Mannheim

L13, 17

68131 Mannheim

GERMANY

ludwig@mea.uni-mannheim.de 


\section{Introduction}

In all major industrialized countries the population is aging, over time reducing the fraction of the population in working age. This process is driven by falling mortality rates followed by a decline in birth rates, which reduces population growth rates (and even turn them negative in some countries). While demographic change occurs in all countries in the world, extent and timing differ substantially. Europe and some Asian countries have almost passed the closing stages of the demographic transition process while Latin America and Africa are only at the beginning (Bloom and Williamson, 1998; United Nations, 2002).

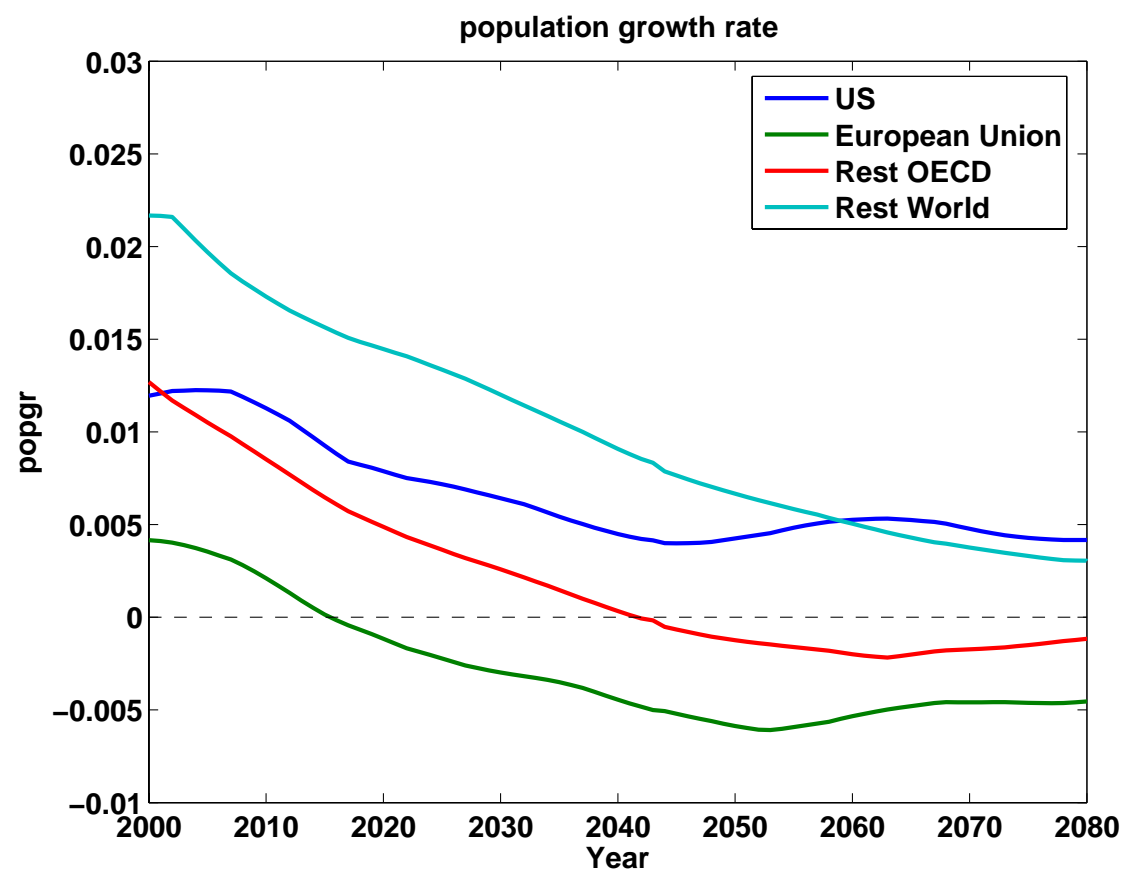

Figure 1: Evolution of the Population Growth Rate in 4 Regions

Figure 1, based on UN population projections, illustrates the differential impact of demographic change on population growth rates (defined here as the growth rate of the adult population) for the period 2000-2080 for four regions of the world that comprise the entire world: the U.S., the European Union (EU), the rest of the OECD (ROECD) and the rest of the world (ROW). Population growth rates are predicted to decline in all regions, but are positive in the U.S. and in the ROW region throughout the 21st century, whereas they fall below zero in the EU in about 2016 and in the ROECD in about 2042. As a consequence, the population in the EU (the ROECD) starts shrinking in about 2016 (2042), 
whereas the population in the other two regions continues to increase.

Figure 2 shows the impact of demographic change on working-age population ratios - the ratio of the working-age population (of age 20-64) to the total adult population (of age 20-95). This indicator, which will turn out to be crucial in our analysis, illustrates that the EU is the oldest, whereas the ROW is the youngest region in terms of the relative size of the working-age population. The United States and the rest of the OECD region initially have the same level of working-age population ratios, but the dynamics of demographic change differ substantially in the U.S. relative to the other regions. While workingage population ratios decrease across all regions, the speed of this decrease significantly slows down for the U.S. in about 2030.

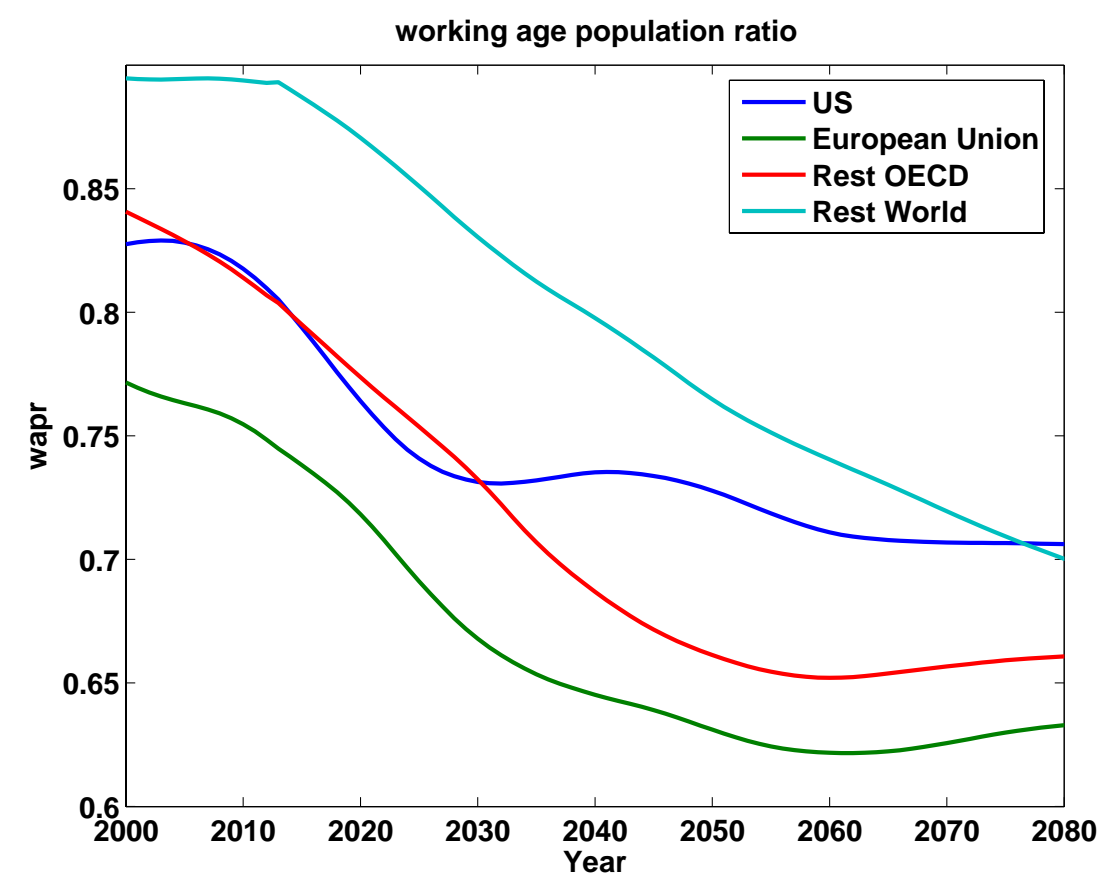

Figure 2: Evolution of Working Age to Population Ratios in 4 Regions

What are the welfare consequences of living in a world where the population is aging rapidly? First, individuals live longer lives and tend to have fewer children, which are the underlying reasons of aging populations. The welfare effects of these changes are hard to quantify. Second, due to changes in the population structure, aggregate labor supply and aggregate savings is bound to change, with ensuing changes in factor prices for labor and capital. Specifically, labor is expected to be scarce, relative to capital, with an ensuing increase in real wages and decline in the real return on capital. The primary objective of this paper is to quantify the distributional and welfare consequences from this 
second, general equilibrium effect of the demographic changes around the world.

To this end, we use demographic projections from the United Nations, together with a large scale Overlapping Generations Model pioneered by Auerbach and Kotlikoff (1987). We extend the model to a multi-country version, as in Börsch-Supan et al. (2006), among many others, and also enrich the model by uninsurable idiosyncratic uncertainty, as in Imrohoroglu et al. (1995), Imrohoroglu et al. (1999), Conesa and Krueger (1999) and others. Both extensions are necessary for the question we want to address. First, uninsurable idiosyncratic uncertainty will endogenously give rise to some agents deriving most of their income from returns to capital, while the income of others is mainly composed of labor income. Abstracting from this heterogeneity does not allow a meaningful analysis of the distributional consequences of changes in factor prices. This feature also adds a precautionary savings motive to the standard life-cycle savings motive of households, which makes life cycle savings profiles generated by the model more realistic. Second, in light of potential differences in the evolution of the age distribution of households across regions, it is important to allow for capital to flow across regions. In our model capital can freely flow between different regions in the OECD (the U.S., the EU and the rest of the OECD). These capital flows may mitigate the decline in rates of return and the increase in real wages one would expect in the U.S. if it were a closed economy.

We find exactly the opposite. In the U.S. as an open economy, rates of return are predicted to decline by 86 basis points between 2005 and 2080. If the U.S. were a closed economy, this decline would amount to only 79 basis points. This result is due to the fact that other regions in the OECD will age even more rapidly. Therefore the U.S. is "importing" the more severe aging problem from these regions via a stronger increase in wages and a stronger decline in interest rates, relative to being a closed economy.

In order to evaluate the welfare consequences of the demographic transition we ask the following question: suppose a household economically born in 2005 would live through the economic transition with changing factor prices induced by the demographic change (but keeping its own survival probabilities constant at their 2005 values), how would its welfare have changed, relative to a situation without a demographic transition? We find that for young households with little assets the increase in wages dominates the decline in rates of return. Abstracting from social security and its reform newborns in 2005 gain in the order of $0.6-0.9 \%$ in terms of lifetime consumption. Older, asset-rich individuals, on the other hand, tend to lose because of the decline in interest rates. If the demographic transition, in addition, makes a reform of the social security system necessary, then falling benefits or increasing taxes reduce the welfare gains for newborn agents. An increase in the retirement age to 70, on the other hand, mitigates some of these negative consequences.

Our paper borrows model elements from, and contributes to, three strands of the literature. Starting with Auerbach and Kotlikoff (1987) a vast number of papers has used large-scale OLG models to analyze the transition path of an economy induced by a policy reform. Examples include social security reform (see e.g. Conesa and Krueger (1999)), fundamental tax reform (see e.g. Altig 
et al. (2001), Conesa and Krueger (2005)) and many others.

A second strand of the literature (often using the general methodology of the first strand) has focused on the economic consequences of population aging in closed economies, often paying special attention to the adjustments required in the social security system due to demographic shifts. Important examples include Huang et al. (1997), De Nardi et al. (1999), and, with respect to asset prices, Abel (2003).

The contributions discussed so far assume that the economy under investigation is closed to international capital flows. However, as the population ages at different pace in various regions of the world one would expect capital to flow across these regions. The third strand of the literature our paper touches upon therefore is the large body of work in international macroeconomics studying the direction, size, cause and consequences of international capital flows and current account dynamics, reviewed comprehensively in Obstfeld and Rogoff (1995).

Our paper is most closely related to work that combines these three strands of the literature, by using the methodology of large scale OLG models to study the consequences of demographic change in open economies. The work by Attanasio et al. (2006b) constructs a two region (the North and the South) OLG model to study the allocative and welfare consequences of different social security reforms in an open economy. Compared to their model, we include endogenous labor supply and idiosyncratic income shocks. While we also have to take a stand on how the social security system deals with the aging of the population, these social security reforms are not in the center of our analysis whereas their paper focuses on this issue. In Attanasio et al. (2006a) the authors quantify the direct welfare losses from demographic changes for the South region of their model, carrying out a similar thought experiment we do for the U.S..

Similar to Attanasio et al. (2006b), but with a stronger focus on Europe or the OECD, Börsch-Supan et al. (2006) and Fehr et al. (2005) investigate the impact of population aging on the viability of the social security system and its reform. Building on earlier work by Brooks (2003) who employs a simple four period OLG model, Henriksen (2002), Feroli (2003) and Domeij and Floden (2005) use large scale simulation models similar to Börsch-Supan et al. (2006) to explain historical capital flow data with changes in demographics, rather than, as we do, to study the (welfare and distributional) implications of future changes in demographics. Relative to this literature, we see the contribution of our paper in evaluating the welfare consequences of the demographic transition per se and not just the alternative social security reform scenarios, as well as in the analysis of the distributional consequences of changing factor prices due to population aging.

The paper is organized as follows. In the next section we construct a simple, analytically tractable multi-country OLG model to isolate the key determinants of international capital flows and the impact of changes in the demographic structure on rates of return and capital flows. Section 3 contains the description of our large scale simulation model. Section 4 discusses the calibration of the model and section 5 presents results for the benchmark model. In section 6 we compare our results to what would be obtained in a closed economy model. 
There we also disentangle the effects from changing fertility and mortality. Section 7 concludes, and separate appendices contain more detailed information about the demographic model underlying our simulations, as well as details of the computational strategy and calibration of the model.

\section{A Simple Model}

We now construct a simple OLG model that is a special case of our quantitative model in the next section. We can characterize equilibria in this model analytically, and are especially interested in the influence of demographic variables and the size of the social security system on rates of return to capital and the dynamics of international capital flows. The results of this simple model will provide some intuition for the quantitative results from the simulation model.

In every country $i$ there are $N_{t, i}$ young households who live for two periods and have preferences over consumption $c_{t, i}^{y}, c_{t+1, i}^{o}$ representable by the utility function

$$
\log \left(c_{t, i}^{y}\right)+\beta \log \left(c_{t+1, i}^{o}\right) .
$$

In the first period of their lives households work for a wage $w_{t, i}$, and in the second period they retire and receive social security benefits $b_{t+1, i}$, financed via payroll taxes on labor income. Thus the budget constraints read as

$$
\begin{aligned}
c_{t}^{y}+s_{t} & =\left(1-\tau_{t, i}\right) w_{t, i} \\
c_{t+1}^{o} & =\left(1+r_{t+1}\right) s_{t}+b_{t+1, i}
\end{aligned}
$$

where $r_{t+1}$ is the real interest rate between period $t$ and $t+1$ and $\tau_{t, i}$ is the social security tax rate in country $i$. We assume that capital flows freely across countries, and thus the real interest rate is equalized across the world.

The production function in each country is given by

$$
Y_{t, i}=K_{t, i}^{\alpha}\left(Z_{i} A_{t} N_{t, i}\right)^{1-\alpha},
$$

where $Z_{i}$ is the country-specific technology level and $A_{t}=(1+g)^{t}$ is exogenously growing productivity. Thus we allow for differences in technology levels across countries, but not its growth rate. We further assume that capital depreciates fully after its use in production.

The production technology in each country is operated by a representative firm that behaves competitively in product and factor markets. Profit maximization of firms therefore implies that

$$
\begin{aligned}
1+r_{t} & =\alpha k_{t}^{\alpha-1} \\
w_{t, i} & =(1-\alpha) Z_{i} A_{t} k_{t}^{\alpha},
\end{aligned}
$$

where

$$
k_{t}=k_{t, i}=\frac{K_{t, i}}{Z_{i} A_{t} N_{t, i}} \forall i
$$

is the capital stock per efficiency unit of labor. 
We assume that the social security system is a pure pay-as-you-go (PAYGO) system that balances the budget in every period. Therefore

$$
\tau_{t, i} w_{t, i} N_{t, i}=b_{t, i} N_{t-1, i} .
$$

Finally, market clearing in the world capital market requires that

$$
K_{t+1}=\sum_{i} K_{t+1, i}=\sum_{i} N_{t, i} s_{t, i}
$$

\subsection{Analysis}

Equilibria in this model can be characterized analytically. To do so we first solve the household problem and then aggregate across households (countries).

\subsubsection{Optimal Household Savings Behavior}

Optimal saving of the young in country $i$ are given as

$$
s_{t, i}=\frac{\beta}{1+\beta} w_{t, i}\left(1-\tau_{t, i}\right)-\frac{b_{t+1, i}}{(1+\beta)\left(1+r_{t+1}\right)} .
$$

The budget constraint of the social security system implies that

$$
b_{t, i}=\frac{N_{t, i}}{N_{t-1, i}} w_{t, i} \tau_{t, i}=\gamma_{t, i}^{N} w_{t, i} \tau_{t, i}
$$

where $\gamma_{t, i}^{N}$ is the gross growth rate of the young cohort in country $i$ between period $t-1$ and $t$. It also measures the working age to population ratio (the higher is $\gamma_{t, i}^{N}$, the higher is that ratio) ${ }^{1}$, which allows us to map the predictions of this model to the data plotted in figure 2. Using the expression for benefits and substituting out for wages and interest rates from (1) in (2) yields

$$
s_{t, i}=\frac{\beta\left(1-\tau_{t, i}\right)(1-\alpha)}{1+\beta} Z_{i} A_{t} k_{t}^{\alpha}-\frac{\gamma_{t+1, i}^{N} \tau_{t+1, i}(1-\alpha)}{(1+\beta) \alpha} Z_{i} A_{t+1} k_{t+1} .
$$

\footnotetext{
${ }^{1}$ The population of a country $i$ at time $t$ is given by

$$
\operatorname{Pop}_{t, i}=N_{t, i}+N_{t-1, i}
$$

and the working age to population ratio is given by

$$
\text { wapr }_{t, i}=\frac{N_{t, i}}{\text { Pop }_{t, i}}
$$

Then we can easily compute the growth rate of the population as

$$
\gamma_{t, i}^{P o p}=\frac{P o p_{t+1, i}}{\operatorname{Pop}_{t, i}}=\frac{1+\gamma_{t, i}^{N}}{1+\frac{1}{\gamma_{t-1, i}^{N}}}
$$

In a balanced growth path $\gamma_{i}^{P o p}=\gamma_{i}^{N}$ and furthermore wapr $_{i}=\frac{1}{1+\frac{1}{\gamma_{i}^{N}}}$. Thus $\gamma_{i}^{N}$ is a measure both of the population growth rate as well as the working age to population ratio.
} 


\subsubsection{Aggregation}

For further reference, define by $\tilde{N}_{t}=\sum_{i} Z_{i} N_{t, i}$ the efficiency weighted world population, by $\tilde{\theta}_{t, i}=\frac{Z_{i} N_{t, i}}{\tilde{N}_{t}}=\frac{\tilde{N}_{t, i}}{\tilde{N}_{t}}$ the relative share of the efficiency-weighted population in country $i$ and by $\tilde{\gamma}_{t}^{N}=\frac{\tilde{N}_{t}}{N_{t-1}}=\sum_{i} \tilde{\theta}_{t, i} \gamma_{t, i}^{N}$ the growth rate of the aggregate (world) efficiency weighted population.

The capital market clearing condition reads

$$
\sum_{i} s_{t, i} N_{t, i}=\sum_{i} K_{t+1, i}=k_{t+1} \sum_{i} Z_{i} A_{t+1} N_{t+1, i}=k_{t+1} A_{t+1} \tilde{N}_{t+1}
$$

Aggregating household savings decisions across countries yields, from (3):

$\sum_{i} s_{t, i} N_{t, i}=\frac{(1-\alpha) \beta A_{t} k_{t}^{\alpha}}{1+\beta} \sum_{i}\left(1-\tau_{t, i}\right) Z_{i} N_{t, i}-\frac{(1-\alpha) A_{t+1} k_{t+1}}{(1+\beta) \alpha} \sum_{i} Z_{i} N_{t+1, i} \tau_{t+1, i}$

Using this in (4) and simplifying yields

$$
k_{t+1}=\sigma_{t} k_{t}^{\alpha}
$$

where

$$
\sigma_{t}=\frac{\alpha(1-\alpha) \beta\left(1-\tau_{t}^{a}\right)}{\tilde{\gamma}_{t+1}^{N} \gamma^{A}\left(\alpha(1+\beta)+(1-\alpha) \tau_{t+1}^{a}\right)}
$$

is the fraction of output per effective worker that is saved. Here $\tau_{t}^{a}=\sum_{i} \tau_{t, i} \tilde{\theta}_{t, i}$ denotes the average social security contribution rate in the world and $\gamma^{A}=1+g$ is the growth rate of technology. Equation (5), as a function of the policy and demographic parameters of the model, describes the dynamics of the aggregate capital stock, given the initial condition $k_{0}{ }^{2}$ Since, from the firms' first order condition, interest rates are given by

$$
1+r_{t}=\alpha k_{t}^{\alpha-1}
$$

the dynamics of the real interest rate are given by

$$
1+r_{t+1}=\left(\frac{\alpha}{\sigma_{t}}\right)^{1-\alpha}\left(1+r_{t}\right)^{\alpha}
$$

with initial condition $1+r_{0}=\alpha k_{0}^{\alpha-1}$.

\subsubsection{Balanced Growth Path Analysis}

A balanced growth path (BGP) is characterized by a constant effective capital stock $k=\sigma^{\frac{1}{1-\alpha}}$ where

$$
\sigma=\frac{\alpha(1-\alpha) \beta\left(1-\tau^{a}\right)}{\tilde{\gamma}^{N} \gamma^{A}\left(\alpha(1+\beta)+(1-\alpha) \tau^{a}\right)}
$$

\footnotetext{
${ }^{2}$ Explicitly, $k_{0}=\frac{\sum_{i} s_{-1, i} N_{-1, i}}{A_{0} \sum_{i} Z_{i} N_{0, i}}$ where $s_{-1, i} N_{-1, i}$ denotes total assets held by the initial old generation in country $i$.
} 
Evidently, normalized and productivity de-trended per capita output in country $i$ is then given by

$$
\frac{Y_{t, i}}{Z_{i} A_{t}\left(N_{t, i}+N_{t-1, i}\right)}=\frac{\sigma^{\frac{\alpha}{1-\alpha}} \gamma_{i}^{N}}{1+\gamma_{i}^{N}} .
$$

To gain further intuition it is instructive to relate rates of return to savings rates along a BGP. World saving (equal to investment) is given by

$$
S_{t}=K_{t+1}-K_{t}
$$

and along a BGP capital grows at a constant rate $\gamma^{A} \tilde{\gamma}^{N}$, so that

$$
S_{t}=\left[\gamma^{A} \tilde{\gamma}^{N}-1\right] K_{t}
$$

Thus the world-wide saving (investment) rate along the BGP is given by

or

$$
\begin{aligned}
s r_{t} & =\frac{S_{t}}{Y_{t}}=\left[\gamma^{A} \tilde{\gamma}^{N}-1\right] \frac{K_{t}}{Y_{t}}=\left[\gamma^{A} \tilde{\gamma}^{N}-1\right] \frac{k_{t} A_{t} \sum_{i} Z_{i} N_{t, i}}{k_{t}^{\alpha} A_{t} \sum_{i} Z_{i} N_{t, i}} \\
& =\left[\gamma^{A} \tilde{\gamma}^{N}-1\right] k^{1-\alpha}=\left[\gamma^{A} \tilde{\gamma}^{N}-1\right] * \frac{\alpha}{1+r}=s r
\end{aligned}
$$

$$
1+r=\frac{\alpha\left[\gamma^{A} \tilde{\gamma}^{N}-1\right]}{s r}
$$

which shows that interest rates and savings rates are negatively related: a higher savings rate, ceteris paribus, increases the supply of capital and thus depresses the rate of return. Of course both the interest rate and the world savings rate are endogenous, and functions of the underlying parameters. It directly follows that along the BGP

$$
\begin{aligned}
s r & =\left[1-\left(\tilde{\gamma}^{N} \gamma^{A}\right)^{-1}\right] \frac{\alpha(1-\alpha) \beta\left(1-\tau^{a}\right)}{\left(\alpha(1+\beta)+(1-\alpha) \tau^{a}\right)} \\
1+r & =\gamma^{A} \tilde{\gamma}^{N} \frac{\left(\alpha(1+\beta)+(1-\alpha) \tau^{a}\right)}{(1-\alpha) \beta\left(1-\tau^{a}\right)}
\end{aligned}
$$

Furthermore, we can characterize international capital flows and the current account. Define savings and investment rates as well as the current account (as fraction of output) in country $i$ as

$$
\begin{aligned}
s r_{t, i} & =\frac{A_{t+1, i}-A_{t, i}}{Y_{t, i}} \\
i r_{t, i} & =\frac{K_{t+1, i}-K_{t, i}}{Y_{t, i}} \\
c a_{t, i} & =s r_{t, i}-i r_{t, i}
\end{aligned}
$$


Along a BGP we can determine, after some tedious algebra,

$$
\begin{aligned}
i r_{i} & =\left[1-\left(\gamma^{A} \gamma_{i}^{N}\right)^{-1}\right] \frac{\gamma_{i}^{N} \alpha(1-\alpha) \beta\left(1-\tau^{a}\right)}{\tilde{\gamma}^{N}\left(\alpha(1+\beta)+(1-\alpha) \tau^{a}\right)} \\
s r_{i} & =\left[1-\left(\gamma^{A} \gamma_{i}^{N}\right)^{-1}\right]\left[\frac{\beta(1-\alpha)\left(1-\tau_{i}\right)}{1+\beta}-\frac{\beta(1-\alpha) \tau_{i}}{(1+\beta)} \frac{\gamma_{i}^{N}(1-\alpha)\left(1-\tau^{a}\right)}{\tilde{\gamma}^{N}\left(\alpha(1+\beta)+(1-\alpha) \tau^{a}\right)}\right] \\
c a_{i} & =\left[1-\left(\gamma^{A} \gamma_{i}^{N}\right)^{-1}\right] \frac{\beta(1-\alpha)\left(1-\tau_{i}\right)}{1+\beta}\left[1-\frac{\gamma_{i}^{N}\left(1-\tau^{a}\right)\left(\alpha(1+\beta)+(1-\alpha) \tau_{i}\right)}{\tilde{\gamma}^{N}\left(1-\tau_{i}\right)\left(\alpha(1+\beta)+(1-\alpha) \tau^{a}\right)}\right]
\end{aligned}
$$

Finally, net foreign asset positions and the current account in the BGP are related according to

$$
\begin{aligned}
C A_{t, i} & =F_{t+1, i}-F_{t, i}=\left[1-\left(\gamma^{A} \gamma_{i}^{N}\right)^{-1}\right] F_{t+1, i} \\
c a_{i} & =\frac{C A_{t, i}}{Y_{t, i}}=\left[1-\left(\gamma^{A} \gamma_{i}^{N}\right)^{-1}\right] f_{i} \text { where } f_{i}=\frac{F_{t+1, i}}{Y_{t, i}}
\end{aligned}
$$

and thus

$$
f_{i}=\frac{\beta(1-\alpha)\left(1-\tau_{i}\right)}{1+\beta}\left[1-\frac{\gamma_{i}^{N}\left(1-\tau^{a}\right)\left(\alpha(1+\beta)+(1-\alpha) \tau_{i}\right)}{\tilde{\gamma}_{N}\left(1-\tau_{i}\right)\left(\alpha(1+\beta)+(1-\alpha) \tau^{a}\right)}\right]
$$

\subsection{Qualitative Predictions from the Simple Model}

In this section we illustrate, using equations (8)-(14), how an aging population (as captured by a decline in $\tilde{\gamma}^{N}$ ), or an increase in social security contribution rates induced by demographic changes (as captured by an increase in $\tau$ ) affects world-wide rates of return, country-specific per capita output, savings and investment rates as well as the current account and the net foreign asset position.

\subsubsection{Rates of Return}

First we determine the consequences of a decline in the working age to population ratio in the BGP. From equation (10) we immediately see that despite the fact that the interest rate and the savings rate are negatively related (see equation (8)), a decline in the working age to population ratio $\tilde{\gamma}^{N}$ leads to both a decline in the rate of return $r$ and in the saving rate $s r$. What is the intuition? A reduction of $\tilde{\gamma}^{N}$ reduces the number of young people relative to old people. Since savings is only done by the young, the savings rate in the economy declines. This makes capital scarce and, ceteris paribus, increases $r$ (see equation 8). But there is the direct effect on the interest rate $r$ : a reduction of $\tilde{\gamma}^{N}$ reduces labor supply tomorrow (as there are fewer young), making labor scarce relative to capital. In the simple model of this section this effect is theoretically shown to dominate, and hence $r$ falls. 
Equation (10) shows another potential, indirect effect from population aging on the interest rate that stems from the social security system. An increase in the (world average) social security contribution rate $\tau^{a}$, by reducing private savings rates, is predicted to drive up rates of return. If policy makers want to keep social security benefits stable despite an aging population, an increase in contribution rates is required. Because this, ceteris paribus, drives up future rates of return, the adjustment of $\tau^{a}$ mitigates or even dominates the direct effect of population aging via a decline of $\tilde{\gamma}^{N}$, as also highlighted by Fehr et al. $(2005) .^{3}$

To summarize, a decline in the world-wide working age to population ratio leads to a decline in rates of return to capital, as long as social security contribution rates are held constant (and thus benefits shrink). If, however, contribution rates are raised in addition, to keep social security benefits stable, the predicted decline in returns is smaller, or returns may even increase. Quantitative work is needed to measure the relative strength of these effects, something we will turn to in the next sections of this paper.

\subsubsection{Per Capita Output}

The simple decomposition in equation (7) illustrates the various channels through which demographic change affects per capita output in country $i$. As the most direct effect, a decrease in the working age to population ratio in country $i$ as measured by $\gamma_{i}^{N}$ leads to a decrease of the overall population which means that the existing resources have to be shared by less people. However, the decrease of the working age to population ratio also directly reduces the labor force which suppresses overall output. An additional positive effect on per capita output stems from capital depending because decreasing $\gamma_{i}^{N}$, through its effect on $\tilde{\gamma}^{N}$, leads to an increase of $\sigma$ and thereby to an increase of the long-run capital capital stock per efficient worker, $k$. Finally, an additional indirect effect already familiar from the above discussion on rates of return emanates from increases in contribution rates, $\tau^{a}$, if social security benefit levels were to be maintained. This harms capital accumulation. Again, quantitative work is needed to measure the relative strengths of these various effects.

\subsubsection{Net Foreign Asset Positions}

Finally we want to deduce the implications of the simple model for the current account and net foreign asset positions across countries. First we observe from equations (13) and (14) that if all countries are identical with respect to their demographic structure and size of the social security system, then the current account and the net foreign asset positions are equal to zero. Thus the

\footnotetext{
${ }^{3}$ The preceding analysis also holds outside the balanced growth path, as equation (6) shows. Since $k_{t}$ and hence $r_{t}$ is predetermined, we observe from equation (6) that the response of $r_{t+1}$ depends negatively on the world saving rate $\sigma_{t}$, which is itself a negative function of the efficiency-weighted population growth rate $\tilde{\gamma}_{t+1}^{N}$ between period $t$ and $t+1$ and a positive function of the social security contribution rate $\tau_{t+1}^{a}$. The same qualitative predictions as in the BGP follow.
} 
only reason for capital to flow across countries in our model are differences in demographics and in the size of the social security system.

What are the consequences of a reduction in the working age to population ratio $\gamma_{i}^{N}$, abstracting from social security (that is, setting $\tau_{i}=\tau^{a}=0$ ) ? ${ }^{4} \mathrm{We}$ observe from equations (11) and (12) that both investment as well as savings rates decline with a decrease in $\gamma_{i}^{N}$, for the same reason as the world savings rate decreased above. What happens to the current account and the net foreign asset position of country $i$ depends on whether it is aging faster or slower than the rest of the world. If all countries age at the same speed (the ratio $\gamma_{i}^{N} / \tilde{\gamma}^{N}$ remains unchanged) then the net foreign asset position remains unchanged and the current account declines in absolute value. If, on the other hand, country $i$ ages faster than the rest $\left(\gamma_{i}^{N} / \tilde{\gamma}^{N}\right.$ decreases), then its net foreign asset position and its current account increase: capital flows from regions that are aging faster to regions that are aging slower. Notice that the term $\gamma_{i}^{N} / \tilde{\gamma}^{N}$ appears in equation (11) but not in equation (12) which illustrates that the strength of demographic change in country $i$ relative to the other world regions directly affects investment rates but not savings rates.

Finally, if all countries have identical working age to population ratios $\left(\gamma_{i}^{N} / \tilde{\gamma}^{N}\right.$ remains at 1 ), but country $i$ increases its social security contribution rate $\tau_{i}$ then (assuming for simplicity $\tau^{a}=0$ ) we observe from equations (11)-(14) that country $i$ 's investment rate remains unchanged, its private savings rate $s r_{i}$ declines, and with it the current account and the net foreign asset position. We will later use these qualitative predictions from the simple model to interpret our results from the quantitative model to which we turn next.

\section{The Quantitative Model}

In this section we describe the quantitative model we use to evaluate the consequences of demographic changes for international capital flows, returns to capital and wages, as well as the welfare consequences emanating from these changes. In our quantitative work we consider three countries/regions: the United States (U.S.), the European Union (EU) and the rest of the OECD (ROECD).

\subsection{Demographics}

The demographic evolution in our model is taken as exogenous (i.e. we do not model fertility, mortality or migration) and is the main driving force of our model. Households start their economic life at age 20, retire at age 65 and live at most until age 95. Since we do not model childhood of a household explicitly, we denote its twentieth year of life by $j=0$, its retirement age by $j r=45$ and the terminal age of life by $J=75$. Households face an idiosyncratic, time- and country-dependent (conditional) probability to survive from age $j$ to age $j+1$, which we denote by $s_{t, j, i}$.

\footnotetext{
${ }^{4}$ Most of these results can be shown under the less restrictive assumption that $\tau_{i}=\tau^{\alpha} \neq 0$.
} 
For each country $i$ we have data or forecasts for populations of model age $j \in\{0, \ldots, 75\}$ in years $1950, \ldots, 2300$. From now on we denote year 1950 as our base year $t=0$ and year 2300 as the final period $T$ and the demographic data for periods $t \in\{0, \ldots, T\}$ by $N_{t, j, i}$. For simplicity, we assume that all migration takes place at or before age $j=0$ in the model (age 20 in the data), so that we can treat migrants and agents born inside the country of interest symmetrically.

\subsection{Technology}

In each country the single consumption good is being produced according to a standard neoclassical production function

$$
Y_{t, i}=Z_{i} K_{t, i}^{\alpha}\left(A_{t} L_{t, i}\right)^{1-\alpha},
$$

where $Y_{t, i}$ is output in country $i$ at date $t, K_{t, i}$ and $L_{t, i}$ are capital and labor inputs and $A_{t}$ is total labor productivity, growing at a constant country independent rate $g$. The scaling parameters $Z_{i}$ control relative total factor productivities across countries, whereas the parameter $\alpha$ measures the capital share and is assumed to be constant over time and across countries. In each country capital used in production depreciates at a common rate $\delta$. Since production takes place with a constant-returns to scale production function and since we assume perfect competition, the number of firms is indeterminate in equilibrium and, without loss of generality, we assume that a single representative firm operates within each country.

\subsection{Endowments and Preferences}

Households value consumption and leisure over the life cycle $\left\{c_{j}, 1-l_{j}\right\}$ according to a standard time-separable utility function

$$
E\left\{\sum_{j=0}^{J} \beta^{j} u\left(c_{j}, 1-l_{j}\right)\right\},
$$

where $\beta$ is the raw time discount factor and expectations are taken over idiosyncratic mortality shocks and stochastic labor productivity. In particular, the expectations operator $E$ encompasses the survival probabilities $s_{t, j, i}$.

Households are heterogenous with respect to age, a deterministic earnings potential and stochastic labor productivity. These sources of heterogeneity affect a household's labor productivity which is given by

$$
\theta_{k} \varepsilon_{j} \eta \text {. }
$$

First, households labor productivity differs according to their age: $\varepsilon_{j}$ denotes average age-specific productivity of cohort $j$. Second, each household belongs to a particular group $k \in\{1, \ldots, K\}$ that shares the same average productivity 
$\theta_{k}$. Differences in groups stand in for differences in education or ability, characteristics that are fixed at entry into the labor market and affect a group's relative wage. We introduce these differences in order to generate part of the cross-sectional income and thus wealth dispersion that does not come from our last source of heterogeneity, idiosyncratic productivity shocks. Lastly, a household's labor productivity is affected by an idiosyncratic shock, $\eta \in\{1, \ldots, E\}$ that follows a time-invariant Markov chain with transition probabilities

$$
\pi\left(\eta^{\prime} \mid \eta\right)>0
$$

We denote by $\Pi$ the unique invariant distribution associated with $\pi$.

\subsection{Government Policies}

The government collects assets of households that die before age $J$ and redistributes them in a lump-sum fashion among the citizens of the country as accidental bequests, $h_{t, i}$ (inheritances). Furthermore, we explore how our results are affected by the presence and the design of a pure pay-as-you-go public pension system, whose taxes and benefits have to be adjusted to the demographic changes in each country. The social security system is modelled as follows. On the revenue side, households pay a flat payroll tax rate $\tau_{t, i}$ on their labor earnings. Retired households receive benefits, $b_{t, k, i}$, that are assumed to depend on the household type, $\theta_{k}$, but are independent of the history of idiosyncratic productivity shocks. Pension benefits are therefore given by

$$
b_{t, k, i}=\rho_{t, i} \theta_{k}\left(1-\tau_{t, i}\right) w_{t, i}
$$

where $\rho_{t, i}$ is the pension system's net replacement rate.

We assume that the budget of the pension system is balanced at all times such that taxes and benefits are related by

$$
\tau_{t, i} w_{t, i} L_{t, i}=\sum_{k} b_{t, k, i} \sum_{j \geq j r} N_{t, j, k, i},
$$

where $N_{t, j, k, i}$ denotes the population in country $i$ at time $t$ of age $j$ and type $k$.

In our results section we distinguish between three different scenarios for the future evolution of the social security system, one in which taxes are held constant and replacement rates adjust accordingly, and vice versa. A third scenario models an increase in the retirement age (and in addition adjusts benefits, if needed, to assure budget balance). The results from the simple model above suggests that our results will be significantly affected by the modelling choice for social security.

\subsection{Market Structure}

In each period there are spot markets for the consumption good, for labor and for capital services. While the labor market is a national market where labor 
demand and labor supply are equalized country by country, the markets for the consumption good and capital services are international where goods and capital flow freely, and without any transaction costs, between countries. The supply of capital for production stems from households in all countries who purchase these assets in order to save for retirement and to smooth idiosyncratic productivity shocks. As sensitivity analysis, we explore how countries would be affected by their demographic changes if they were closed economies where capital stocks and accumulated assets coincide by definition.

\subsection{Equilibrium}

Individual households, at the beginning of period $t$ are indexed by their age $j$, their group $k$, their country of origin $i$, their idiosyncratic productivity chock $\eta$, and their asset holdings $a$. Thus their maximization problem reads as

$$
\begin{aligned}
& W(t, j, k, i, \eta, a) \\
&= \max _{c, a^{\prime}, 1-l}\left\{u(c, 1-l)+\beta s_{t, j, i} \sum_{\eta^{\prime}} \pi\left(\eta^{\prime} \mid \eta\right) W\left(t+1, j+1, k, i, \eta^{\prime}, a^{\prime}\right)\right\} \\
& \text { s.t. } c+a^{\prime}= \begin{cases}\left(1-\tau_{t, i}\right) w_{t, i} \theta_{k} \varepsilon_{j} \eta l+\left(1+r_{t}\right)\left(a+h_{t, i}\right) & \text { for } j<j r \\
b_{t, k, i}+\left(1+r_{t}\right)\left(a+h_{t, i}\right) & \text { for } j \geq j r\end{cases} \\
& a^{\prime}, c \geq 0 \text { and } l \in[0,1] .
\end{aligned}
$$

Here $w_{t, i}$ is the wage rate per efficiency unit of labor and $r_{t}$ is the real interest rate. We denote the cross-sectional measure of households in country $i$ at time $t$ by $\Phi_{t, i}$. We can then define a competitive equilibrium as follows.

Definition 1 Given initial capital stocks and measures $\left\{K_{0, i}, \Phi_{0, i}\right\}_{i \in I}$, a competitive equilibrium are sequences of individual functions for the household, $\left\{W(t, \cdot), c(t, \cdot), l(t, \cdot), a^{\prime}(t, \cdot)\right\}_{t=0}^{\infty}$, sequences of production plans for firms $\left\{L_{t, i}, K_{t, i}\right\}_{t=0, i \in I}^{\infty}$, policies $\left\{\tau_{t, i}, \rho_{t, i}, b_{t, i}\right\}_{t=0, i \in I}^{\infty}$, prices $\left\{w_{t, i}, r_{t}\right\}_{t=0, i \in I}^{\infty}$, transfers $\left\{h_{t, i}\right\}_{t=0, i \in I}^{\infty}$ and measures $\left\{\Phi_{t, i}\right\}_{t=0, i \in I}^{\infty}$ such that

1. Given prices, transfers and initial conditions, $W(t, \cdot)$ solves equation (17), and $c(t, \cdot), l(t, \cdot), a^{\prime}(t, \cdot)$ are the associated policy functions.

2. Interest rates and wages satisfy

$$
\begin{aligned}
r_{t} & =\alpha Z_{i}\left(\frac{K_{t, i}}{A_{t} L_{t, i}}\right)^{\alpha-1}-\delta \\
w_{t, i} & =(1-\alpha) Z_{i} A_{t}\left(\frac{K_{t, i}}{A_{t} L_{t, i}}\right)^{\alpha} .
\end{aligned}
$$

3. Transfers are given by

$$
h_{t+1, i}=\frac{\int\left(1-s_{t, j, i}\right) a^{\prime}(t, j, k, i, \eta, a) \Phi_{t, i}(d j \times d k \times d \eta \times d a)}{\int \Phi_{t+1, i}(d j \times d k \times d \eta \times d a)}
$$


4. Government policies satisfy (15) and (16) in every period.

5. Markets clear in all $t, i$

$$
\begin{aligned}
& L_{t, i}=\int \theta_{k} \varepsilon_{j} \eta l(t, j, k, i, \eta, a) \Phi_{t, i}(d j \times d k \times d \eta \times d a) \text { for all } i \\
& \sum_{i=1}^{I} K_{t+1, i}=\sum_{i=1}^{I} \int a^{\prime}(t, j, k, i, \eta, a) \Phi_{t, i}(d j \times d k \times d \eta \times d a) \text { for all } i \\
& \sum_{i=1}^{I} \int c(t, j, k, i, \eta, a) \Phi_{t, i}(d j \times d k \times d \eta \times d a)+\sum_{i=1}^{I} K_{t+1, i} \\
= & \sum_{i=1}^{I} A_{t, i} K_{t, i}^{\alpha} L_{t, i}^{1-\alpha}+(1-\delta) \sum_{i=1}^{I} K_{t, i} \text { for all } i .
\end{aligned}
$$

6. The cross-sectional measures $\Phi_{t, i}$ evolve as

$$
\Phi_{t+1, i}(\mathcal{J} \times \mathcal{K} \times \mathcal{E} \times \mathcal{A})=\int P_{t, i}((j, k, \eta, a), \mathcal{J} \times \mathcal{K} \times \mathcal{E} \times \mathcal{A}) \Phi_{t, i}(d j \times d k \times d \eta \times d a)
$$

for all sets, $\mathcal{J}, \mathcal{K}, \mathcal{E}, \mathcal{A}$, where the Markov transition functions $P_{t, i}$ are given by

$$
P_{t, i}((j, k, \eta, a), \mathcal{J} \times \mathcal{K} \times \mathcal{E} \times \mathcal{A})=\left\{\begin{array}{cc}
\pi(\eta, \mathcal{E}) s_{t, j, i} & \text { if } a^{\prime}(t, j, k, i, \eta, a) \in \mathcal{A} \\
0 & k \in \mathcal{K}, j+1 \in \mathcal{J} \\
& \text { else }
\end{array}\right.
$$

and for newborns

$$
\Phi_{t+1, i}(\{1\} \times \mathcal{K} \times \mathcal{E} \times \mathcal{A})=N_{t+1,0, i} \cdot\left\{\begin{array}{cc}
\Pi(\mathcal{E}) & \text { if } 0 \in \mathcal{A} \\
0 & \text { else }
\end{array} .\right.
$$

Definition 2 A stationary equilibrium is a competitive equilibrium in which all individual functions are constant over time and all aggregate variables grow at a constant rate.

\subsection{Thought Experiment and Computation}

We take as exogenous driving process a time-varying demographic structure in all regions under consideration. We allow country-specific survival, fertility and migration rates to change over time, inducing a demographic transition from an initial distribution towards a final steady state population distribution that arises once all changes in these rates have been completed and the population structure has settled down to its new steady state. Induced by this transition of the population structure is a transition path of the economies of the model, both in terms of aggregate variables as well as cross-sectional distributions of wealth and welfare. Summary measures of these changes will provide us with 
answers as to how the changes in the demographic structure of the economy, by changing returns to capital and wages, impact the distribution of welfare.

We start computations in year 1950 assuming an artificial initial steady state. We then use data for a calibration period, 1950-2004, to determine several structural model parameters (see section 4 ). We then compute the model equilibrium from 1950 to 2300 (when the new steady state is assumed and verified to be reached) and report simulation results for the main projection period of interest, from 2005 to 2080. For given structural model parameters we solve for the equilibrium using a modification of the familiar Gauss-Seidel algorithm (see Ludwig, 2006). Throughout we take as length of the period one year. Appendix $\mathrm{B}$ contains a detailed description of our computational procedure.

\section{Calibration}

In this section we discuss our specification of the model parameters. We need to choose parameters governing the demographic transition, the production technology, endowments and preferences, and the social security policy.

\subsection{Demographics}

Our demographic processes are based on the United Nations world population projections (United Nations, 2001). These numbers determine both the idiosyncratic survival probabilities as well as the relative sizes of total populations in the regions in all time periods under consideration. Figures 1 and 2 in the introduction summarized the main stylized facts from these population figures, and appendix A describes in detail the methodology underlying our demographic projections.

\subsection{Technology}

We restrict the capital share parameter, $\alpha$, the growth rate of labor productivity, $g$, and the depreciation rate, $\delta$, to be constant across all regions under consideration, whereas we allow technology levels $Z_{i}$ to differ across regions. The parameters characterizing production technologies in different countries can therefore be collected as

$$
\vec{\Psi}^{P S}=\left[\alpha, g, \delta, Z_{1}, Z_{2}, Z_{3}\right]^{\prime}
$$

We estimate parameters $\alpha, g$ and $\delta$ using U.S. NIPA data for a sample period of $1960-2004$, set $Z_{1}=1$ and estimate $Z_{2}, Z_{3}$ taking data on relative labor productivity across regions. A more detailed description of our approach is given in appendix B.3. Table I summarizes the resulting parameter estimates. 


\begin{tabular}{|l|c|c|c|}
\hline \multicolumn{3}{|c|}{ Table I: Technology Parameters } \\
\hline Parameter & U.S. & EU & ROECD \\
\hline Capital Share $\alpha$ & \multicolumn{3}{|c|}{0.33} \\
\hline Growth Rate of Technology $g$ & \multicolumn{3}{|c|}{0.018} \\
\hline Depreciation Rate $\delta$ & \multicolumn{3}{|c|}{0.04} \\
\hline Total Factor Productivity $Z_{i}$ & 1.0 & 0.88 & 0.65 \\
\hline
\end{tabular}

\subsection{Endowments and Preferences}

Households start their life with zero assets and are endowed with one unit of time per period. Labor productivity is given by the product of three components, a deterministic age component $\varepsilon_{j}$, a deterministic group component $\theta_{k}$ and a stochastic idiosyncratic component $\eta$.

The age-productivity profile $\left\{\varepsilon_{j}\right\}_{j=1}^{J}$ is taken from Hansen (1993) and generates an average life-cycle wage profile consistent with U.S. data. In experiments where we extend the retirement age we linearly extrapolate the efficiency profile beyond age 65 .

Conditional on age, the natural logarithm of wages is given by

$$
\log \left(\theta_{k}\right)+\log (\eta)
$$

We choose the number of groups to be $K=2$ and let groups be of equal size. We choose $\left\{\theta_{1}, \theta_{2}\right\}$ such that average-group productivity is equal to 1 and the variance of implied labor incomes of entrants to the labor market coincides with that reported by Storesletten et al. (2004). This requires $\theta_{1}=0.57$ and $\theta_{2}=1.43$. For the idiosyncratic part of labor productivity we use a 2 state Markov chain with annual persistence of 0.98 and implied conditional variance of $8 \%$, again motivated by the findings of Storesletten et al. (2004).

We assume that the period utility function is of the familiar CRRA form given by

$$
u(c, l)=\frac{1}{1-\sigma}\left(c^{\omega_{i}}(1-l)^{1-\omega_{i}}\right)^{1-\sigma},
$$

where $\sigma$ denotes the coefficient of relative risk aversion and where $\omega_{i}$ measures the importance of consumption, relative to leisure in each country. Differences in $\omega_{i}$ across countries allow us to match simulated hours worked to the actual data separately for each country. In addition we have to specify the time discount factor of households which we restrict to be identical across countries.

The preference parameters can accordingly be summarized as

$$
\vec{\Psi}^{H S}=\left[\sigma, \beta, \omega_{1}, \omega_{2}, \omega_{3}\right]^{\prime} .
$$

We assume $\sigma=1$ such that utility is separable between consumption and leisure, and determine the value of the discount rate by matching the average simulated capital-output ratio to U.S. data for the period 1960-2004. The consumption share parameters $\omega_{i}$ are estimated by matching simulated average hours worked in the regions of our model to the data. A more detailed description of our 
methodology is given in appendix B.3. Table II summarizes the preference parameters for the version of our model where a pension system is present. ${ }^{5}$

\begin{tabular}{|l|c|c|c|}
\hline \multicolumn{4}{|c|}{ Table II: Preference Parameters } \\
\hline Parameter & U.S. & EU & ROECD \\
\hline Coefficient of RRA $\sigma$ & \multicolumn{3}{|c|}{1.0} \\
\hline Time Discount Factor $\beta$ & \multicolumn{3}{|c|}{0378} \\
\hline Consumption Share Parameter $\omega_{i}$ & 0.463 & 0.446 & 0.442 \\
\hline
\end{tabular}

\subsection{Social Security System}

Our benchmark model contains no social security system. The version of the model used most prominently in our welfare calculations contains the PAYGO social security system, uses historical data for social security tax rates in the three regions of interest until 2004 and then freezes future contribution rates at their 2004 levels. Benefits adjust to achieve budget balance. In the alternative scenario of fixed replacement rates we again use historical region-specific data on contribution rates to back out constructed replacement rates until 2004 and then fix replacement rates in the future to their 2004 values. Tax rates increase to assure budget balance of the social security system.

Data for calibrating the social security system are taken from various sources. For the U.S., we calculate social security contribution rates from NIPA data taken from the BEA (Table 3.6). It is more difficult to obtain data for the other world regions. We proxy the time path of social security contribution rates by using time path information on total labor costs taken from the BLS and scale these data by social security contribution rates from the OECD for the other regions of interest.

\section{Results for the Benchmark Model}

In order to isolate the direct effects of demographic changes on returns to capital, international capital flows, and the distribution of wealth and welfare we first abstract from social security. In section 5.5 we then quantify the additional effects that are implied by the adjustments of social security parameters to demographic change. In the benchmark scenario we also assume that capital flows freely only between regions in the OECD, and we document in section 6.1 how our results are affected if these regions would be closed economies.

\subsection{Steady State Comparison}

In order to obtain first sense for the impact of changes in demographics on the economy, table III compares the main economic aggregates between the initial

\footnotetext{
${ }^{5}$ For each alternative version of our model all household model parameters are recalibrated to match the same aggregate data described above. Estimated parameter values for these alternative versions are similar to those reported in table II.
} 
steady state in 1950 and the final steady state in 2300 . Here $\bar{l}$ denotes average hours worked per person in working age. The table, which displays percentage changes between the new and the old steady state (for the interest rate and average hours percentage point differences are shown), documents a substantial decline in real rates of return between the old steady state in 1950 and the new steady state in 2300 by more than 300 basis points. Detrended real wages, on the other hand, increase by $14 \%$, resulting from substantial capital deepening. These findings are exactly what our simple model led us to expect. As the discussion of equation (7) in the analysis of the simple model already showed, the long run consequences for output (income) per capita are less clear. On the one hand, output per worker increases substantially (due to a shrinking population, capital deepening and slightly increased age-specific labor supply shares), but, on the other hand, the fraction of the population that works declines. Table III demonstrates that detrended output per capita declines slightly in the long run, suggesting that the aging effect dominates the capital deepening effect. ${ }^{6}$

\begin{tabular}{|l|r|r|r|}
\hline \multicolumn{4}{|c|}{ Table III: Steady State Comparison } \\
\hline Variable & United States & Eur. Union & Rest OECD \\
\hline$r$ & $-3.06 \%$ & $-3.06 \%$ & $-3.06 \%$ \\
\hline$w$ & $14.1 \%$ & $14.1 \%$ & $14.1 \%$ \\
\hline$Y / N$ & $-2.23 \%$ & $-0.10 \%$ & $-5.8 \%$ \\
\hline$l$ & $5.4 \%$ & $6.0 \%$ & $4.1 \%$ \\
\hline
\end{tabular}

The effects documented in table III incorporate the entire demographic transition. In our subsequent analysis we now zoom in on our main period of interest, the next 75 years. Since only a part of the dramatic aging of the population falls into this period we expect the same qualitative, but quantitatively smaller effects.

\subsection{Dynamics of Aggregate Statistics}

In figure 3 we display the evolution of the real return to capital from 2000 to 2080. In the same figure we plot, as a summary measure of the age structure of the population, the fraction of the world adult population with age above 65 (by assumption these agents are retired in our model); this statistic is one minus the working age to population ratio. We observe that the rate of world-wide return to capital is predicted to fall by almost 1 percentage point in the next 60 years

\footnotetext{
${ }^{6}$ Output per capita declines least for the EU in the long run since hours worked per person decline least. This is due to the assumption that in the long run, towards the new steady state, fertility rates in the EU will rebound so that the decrease in working age to population ratios is roughly the same in the US and the EU in the long run. In addition, working households increase their hours by more in the EU, relative to the US since their initial steady state level of labor supply is lower and thus they face lower marginal costs of working extra hours.

Since the rebound of fertility rates in the EU does not occur in the next 75 years and thus working-age to population ratios decline much more strongly in the EU than in the US in the next 80 years, the transition analysis will paint a different picture along this dimension.
} 
and then to settle down at that lower level. This is exactly what we would have expected, given the qualitative results from the simple model in section 2 , and given the fact that so far we abstract from social security (reform).

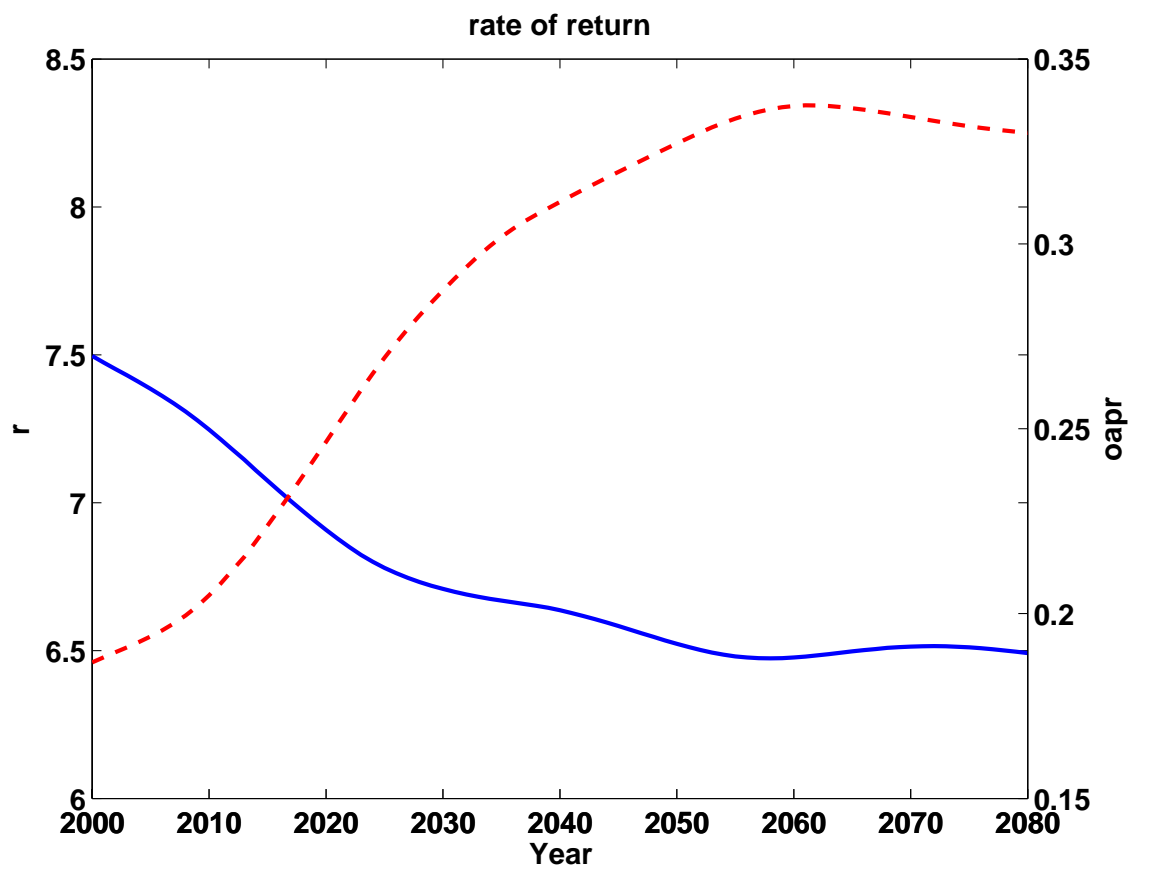

Figure 3: Evolution of World Interest Rates

Pre-tax wages are related to the interest rate by

$$
w_{t, i}=(1-\alpha) Z_{i} A_{t}\left(\frac{\alpha Z_{i}}{r_{t}+\delta}\right)^{\frac{\alpha}{1-\alpha}}
$$

and thus de-trended (by productivity growth) real wages follow exactly the inverse path of interest rates, documented in figure 3 . These de-trended wages are predicted to increase by roughly $4 \%$ between 2000 and 2080 in all regions in our model.

In figure 4 we plot the evolution of de-trended output per capita in the three regions, normalized to 1 in the year 2000. Notice that "per capita" here refers to the adult population aged 20 to 95 . We observe substantial declines of $7-13 \%$ in the three regions. The decline is least pronounced in the U.S., since there the decrease of the fraction of households in working age is more modest after 2030, as we saw in figure 2. During the transition period from 2005-80, the negative effects of decreasing working age to population ratios therefore dominate the positive effects on output per worker (see the discussion of equation (7) in the analysis of the simple model). 


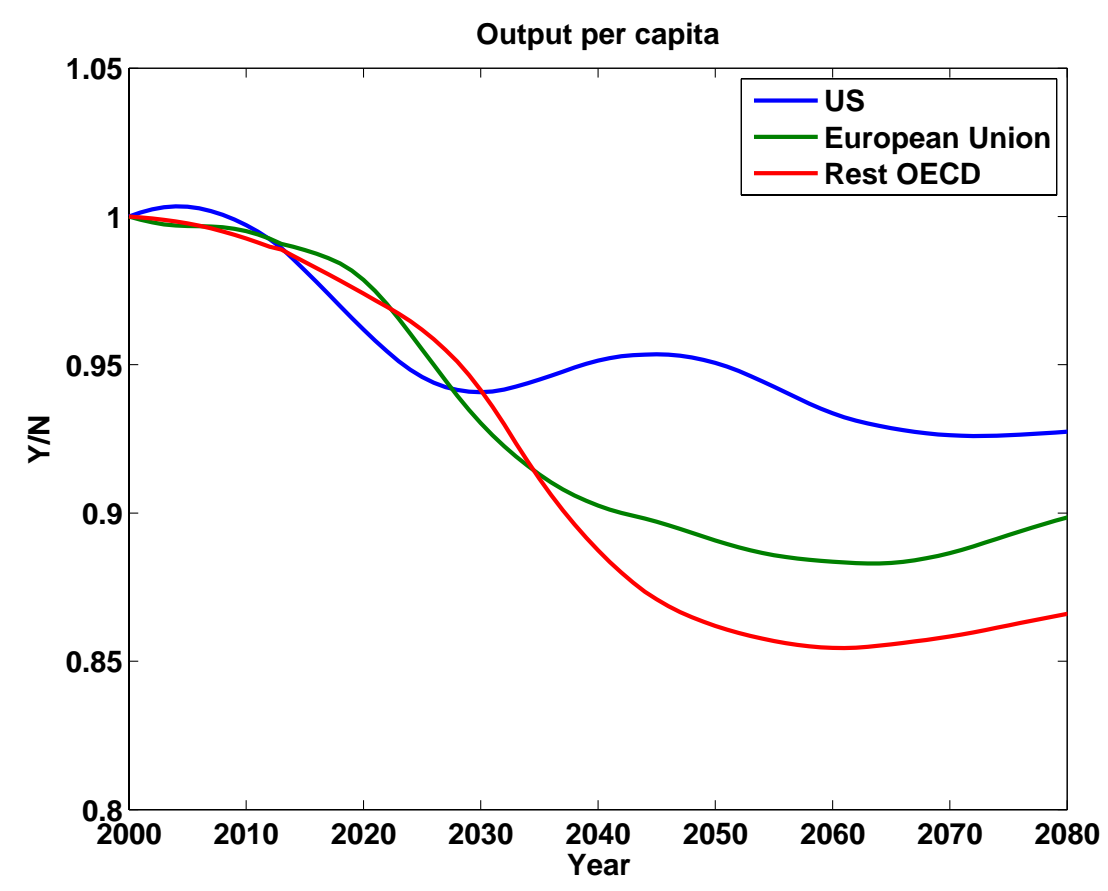

Figure 4: Evolution of GDP per Capita in 3 Regions

\subsection{Quantifying International Capital Flows}

In order to analyze the direction and size of international capital flows we will document the evolution of the net foreign asset position and the current account of the countries/regions under consideration. As in the simple model, the current account is given by the change in the net foreign asset position and thus by the difference of country $i$ 's saving and investment ${ }^{7}$

$$
\begin{aligned}
C A_{t, i} & =F_{t+1, i}-F_{t, i} \\
& =S_{t, i}-I_{t, i} .
\end{aligned}
$$

When reporting these statistics we always divide them by output $Y_{t, i}$. We start with investigating national saving and investment rates and then discuss implied the current account and net foreign asset positions.

\footnotetext{
${ }^{7}$ Note that in a closed economy $F_{t, i}=C_{t, i}=0$, and that in a balanced growth path of an open economy $C A_{t, i}=g\left(A_{t, i}-K_{t, i}\right)$. Furthermore net asset positions and current accounts evidently have to sum to 0 across regions:$$
\sum_{i} F_{t, i}=\sum_{i} C A_{t, i}=0 \text { for all } t
$$ 


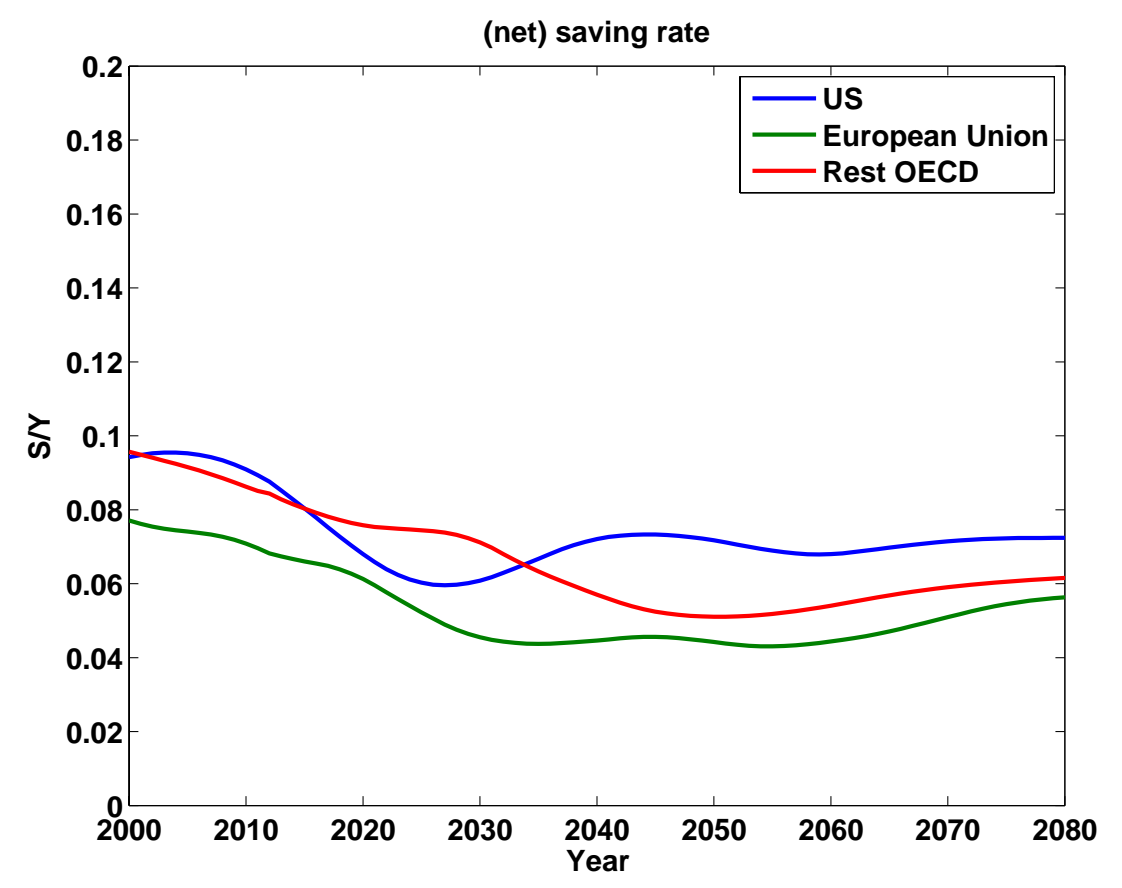

Figure 5: Evolution of Net Saving Saving Rate in 3 Regions

The most direct effect of an aging population is that labor, as a factor of production, becomes scarce. As a result, for unchanged aggregate saving the return to capital has to fall and gross wages have to rise. This is what we observe in figure 3. However, the decline in interest rates may reduce the incentives of households to save, depending on the relative size of the income and substitution effect. In addition, as our simple model suggests, with the aging of society the age composition of the population shifts towards older households, who are dissavers in our life cycle model. Consequently savings rates in all regions in our model decline over time, as shown in figure 5 . For the next 20 years the fall in savings rates is most pronounced for the U.S., because there, during this time period, the large cohort of baby boomers moves into retirement. The same is true for other regions of the world, albeit to a lesser degree on average ${ }^{8}$. After the large cohort of baby boomers have left the economy (i.e. died) the U.S. saving rate is predicted to rebound (in about 25 to 35 years) and then to stabilize, whereas in the European Union and the rest of the OECD savings rates continue to fall until about 2040 and then stabilize.

The other side of the medal (that is, of the current account) is the investment

\footnotetext{
${ }^{8}$ Notice that the evolution of demographic variables and the simulated time paths of savings may differ substantially across the countries within each country block, see, e.g., Börsch-Supan et al. (2005).
} 
behavior in the different regions. Given that savings rates decline globally due to population aging investment rates have to do so as well on average, since the world current account has to balance to 0 . As the population ages and the labor force declines it is optimal to reduce the capital stock with which these fewer workers work. Thus investment rates fall.

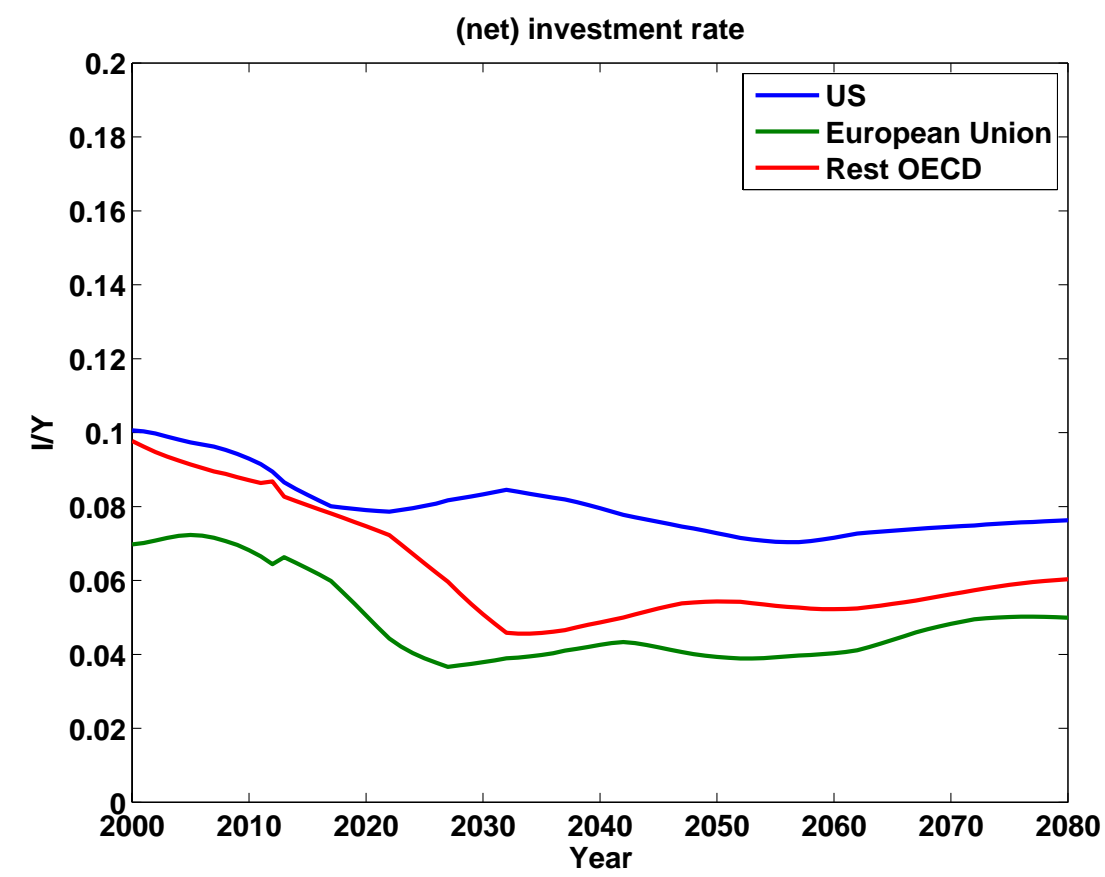

Figure 6: Evolution of Net Investment Rate in 3 Regions

Figure 6 demonstrates this fall for all regions, but also shows that the fall is by far the least pronounced for the U.S. Furthermore, in the U.S., the investment rate stops to fall by about 2020, roughly a decade earlier than its saving rate. This is due to the fact that the fall in the working age to population ratio is completed around that date in the U.S. On the other hand, in the EU and the rest of the OECD this ratio continues to fall until 2035. Since capital-(effective) labor ratios have to be equalized, capital allocated to these regions has to fall (relative to the U.S.) and so do investment rates in these regions.

Figure 7 shows a very clear deterioration of the current account of the U.S. of about $2 \%$ of GDP that is expected to occur in the next 30 years, as capital flows from the European Union and, with a slight time delay, from the rest of the OECD, into the U.S. By 2040 this process is completed and the current account of all countries returns to roughly 0 from that point on. The predicted deterioration in the U.S. current account is due to an investment rate that falls less than in other countries (since the population in the US ages slower and 
thus the labor force falls less) as well as a (temporary) sharp decline in the U.S. savings rate in the next 20 years due to the gradual retirement of the baby boomers (see again figures 5 and 6 ).

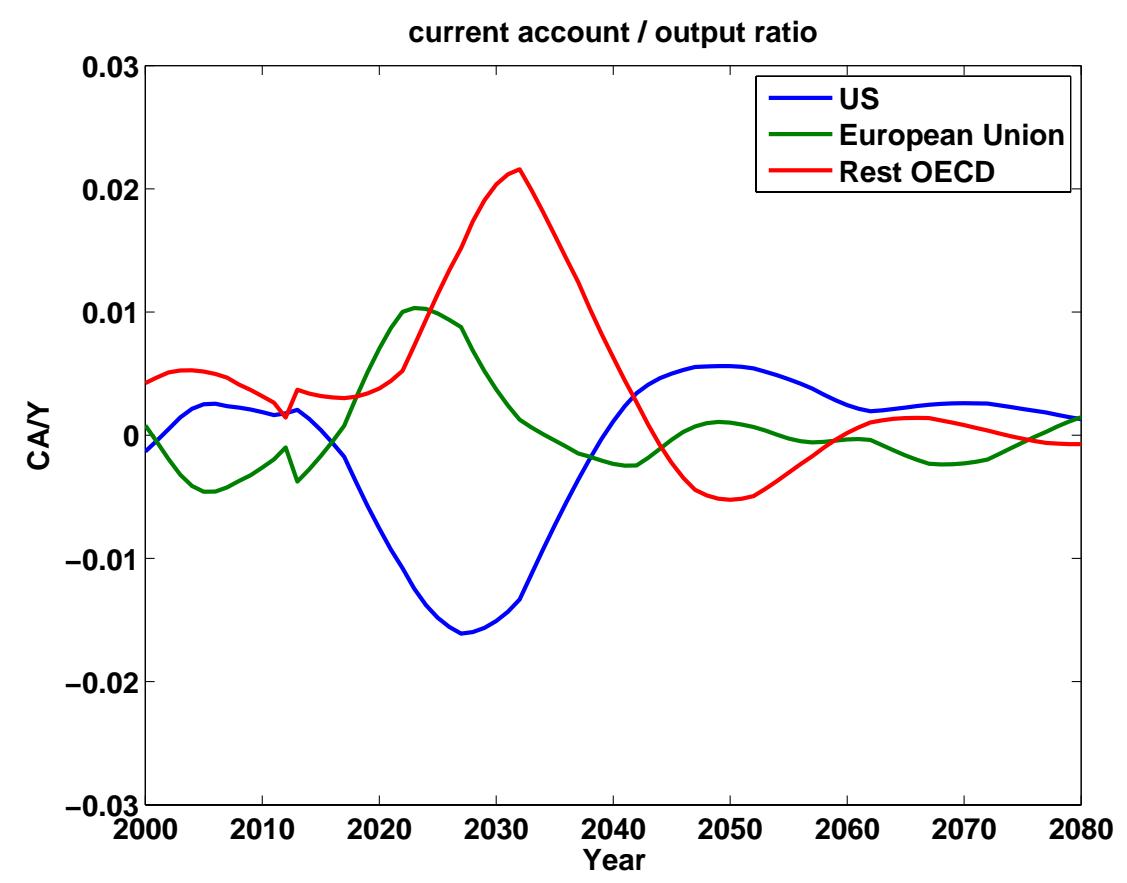

Figure 7: Evolution of the Current Account in 3 Regions

Finally figure 8 shows the evolution of the net foreign asset position, relative to GDP, in the three regions of our model. The European Union, as the oldest region, has a positive net asset position and thus provides capital to both the rest of the OECD and, increasingly, to the U.S.. As the U.S. current account is strongly negative during the years 2020 and 2040, the U.S. net foreign asset position reaches a trough of about $-36 \%$ in about 2040 . Thus the qualitative results from the quantitative model are in line with the predictions of the simple model, coupled with the level and dynamics of the working age to population ratio in the different regions documented in figure 2.

\subsection{Distributional and Welfare Consequences of Demo- graphic Change}

In the previous sections we have documented substantial changes in factor prices induced by the aging of the population, amounting to a decline of about 1 percentage point in real returns to capital and an increase in gross wages of about 


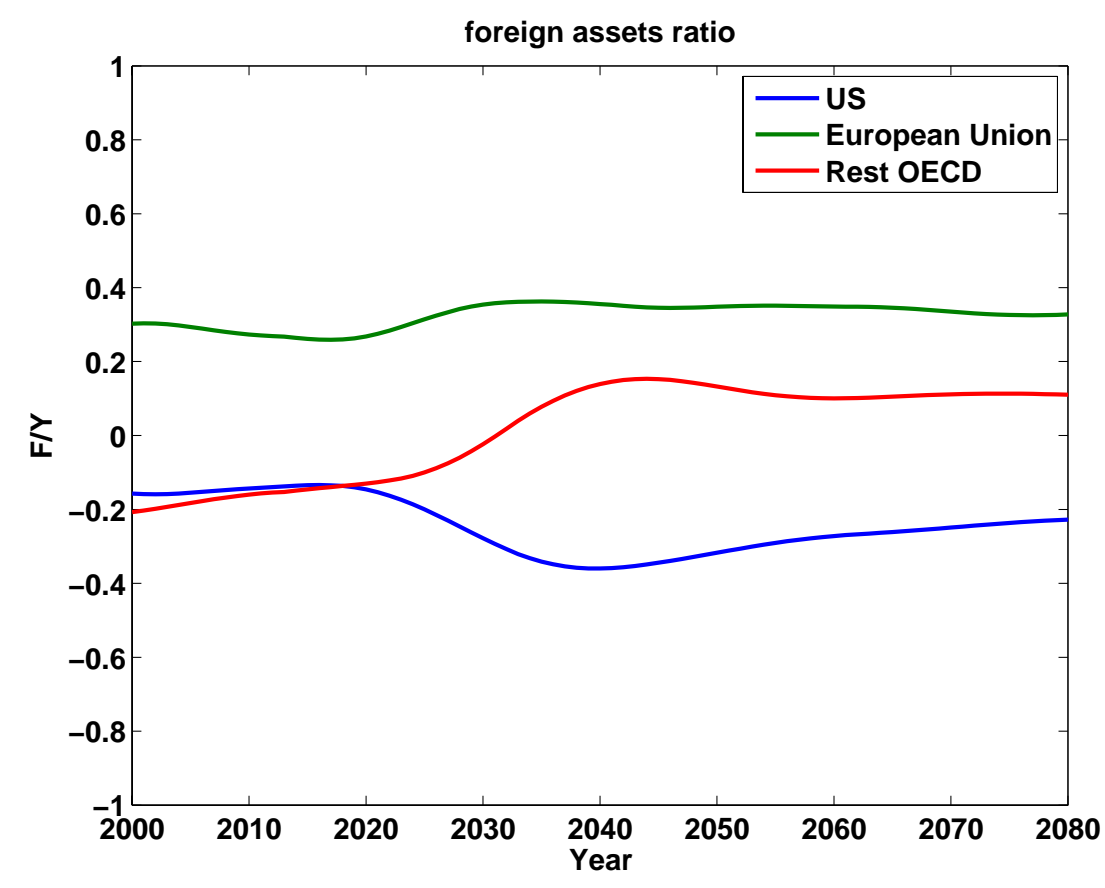

Figure 8: Evolution of the Net Foreign Asset Position in 3 Regions

$4 \%$ in the next decades. In this section we want to quantify the distributional and welfare effects emanating from these changes.

\subsubsection{Evolution of Inequality}

In figure 9 we display the evolution of income inequality over time in the three regions. Income is composed of labor income (which later will include pension income) and capital income as well as transfers from accidental bequests.

We observe a significant increase in income inequality between 2000 and 2080, of about 5 points in the Gini coefficient for the EU and the ROECD and 3.5 points in the U.S.. The reason for this increase is mainly a compositional effect. Retired households have significantly lower income on average than households in working age. The demographic transition towards more retired households therefore is bound to increase inequality, especially in those regions where the increase in the fraction of retired households among the population is very pronounced. This explains the more modest increase in income inequality in the U.S.. Note that consumption inequality follows income inequality trends fairly closely in the three regions (and thus is not shown here), but increases in consumption inequality are less pronounced. Also notice that the ordering of countries in the figure will be reversed once we add pension systems - then, 


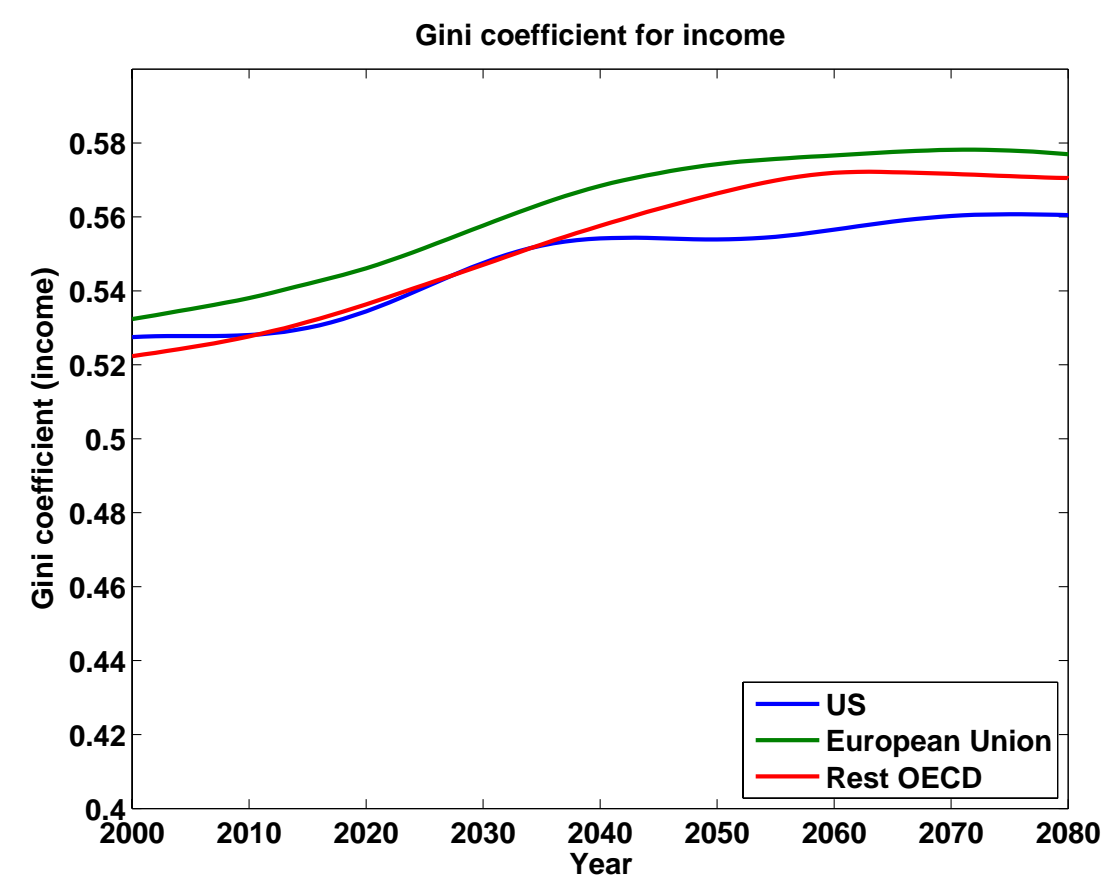

Figure 9: Evolution of Income Inequality in 3 Regions

income will be least equally distributed in the U.S..

The fact that it is not a rise in capital income inequality that drives the increase in total income inequality becomes clear when plotting wealth inequality over time. There is no discernible increase in the same period; evidently the same is true for capital income inequality since capital income is proportional to wealth.

In contrast to income, wealth follows a hump-shaped pattern over the life cycle (on average), with the elderly and the young being wealth-poor. Thus, in contrast to income inequality, the aging of the population does not lead to an increase in wealth inequality, since the demographic change increases the fraction of the elderly, but reduces the fraction of the young. Consequently income and wealth inequality do not follow the same trend over time, nor is the ranking in inequality across regions the same for income and wealth.

We therefore conclude that the opposite general equilibrium effects on wages and interest rates have little impact on the income and wealth distribution across generations. 


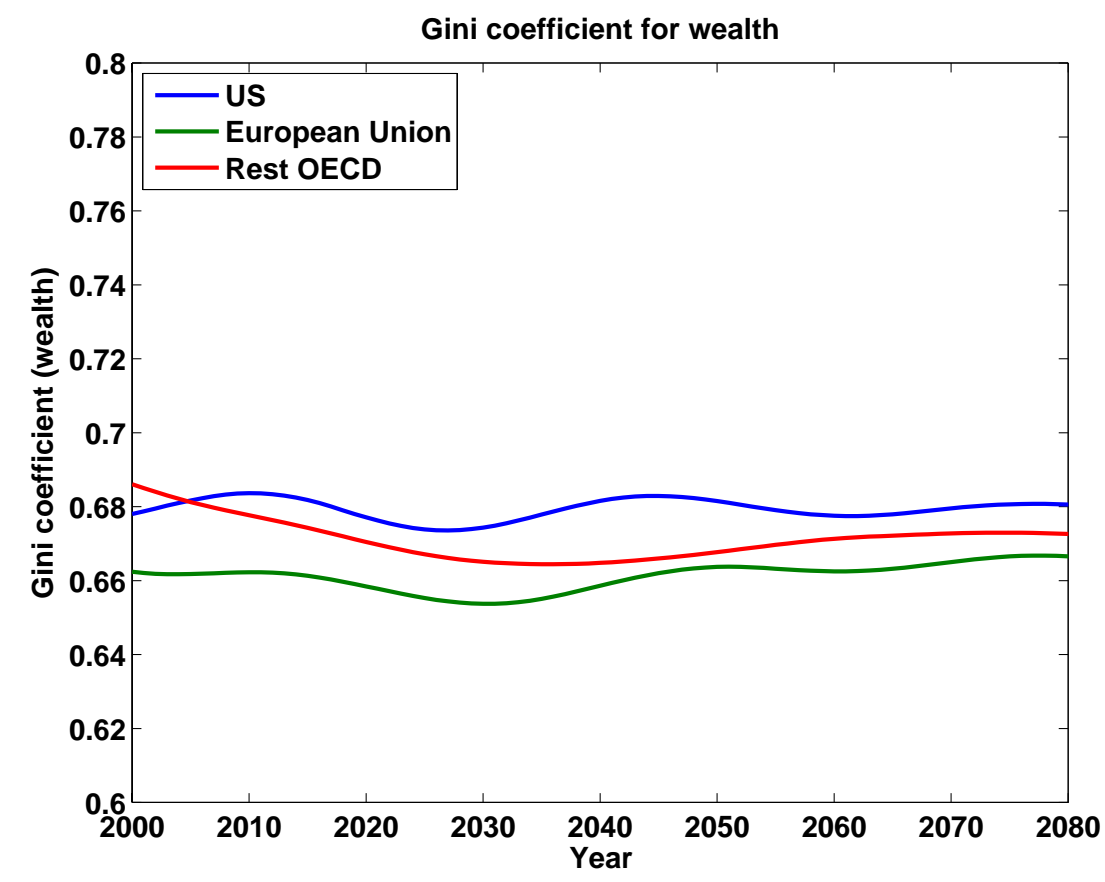

Figure 10: Evolution of Wealth Inequality in 3 Regions

\subsubsection{Welfare Consequences of the Demographic Transition}

A household's welfare is affected by two consequences of demographic change. First, her lifetime utility changes because her own survival probabilities increase; this is in part what triggers the aging of the population. Second, due to the demographic transition she faces different factor prices and government transfers and taxes (from the social security system and from accidental bequests) than without changes in the demographic structure. Specifically, households face a path of declining interest rates and increasing wages, relative to the situation without a demographic transition.

We want to isolate the welfare consequences of the second effect. For this we compare lifetime utility of agents born and already alive in 2005 under two different scenarios. For both scenarios we fix a household's individual survival probabilities at their 2005 values; of course they fully retain their age-dependence. Then we solve each household's problem under two different assumptions about factor prices (and later taxes/transfers, once we have introduced social security). Let $\bar{W}(t, i, j, k, \eta, a)$ denote the lifetime utility of an agent at time $t \geq 2005$ in country $i$ with individual characteristics $(j, k, \eta, a)$ that faces the sequence of equilibrium prices as documented in the previous section, but constant 2005 survival probabilities, and let $\bar{W}_{2005}(t, i, j, k, \eta, a)$ denote the lifetime utility of 
the same agent that faces prices and taxes/transfers that are held constant at their 2005 value. Finally, denote by $g(t, i, j, k, \eta, a)$ the percentage increase in consumption that needs to be given to an agent $(t, i, j, k, \eta, a)$ at each date and contingency in her remaining lifetime (keeping labor supply allocations fixed) at fixed prices to make her as well off as under the situation with changing prices. ${ }^{9}$ Positive numbers of $g(t, i, j, k, \eta, a)$ thus indicate that households obtain welfare gains from the general equilibrium effects of the demographic changes, negative numbers mean welfare losses. Of particular interest are the numbers $g(t=56, i, j=0, k, \eta, a=0)$, that is, the welfare consequences for newborn agents in $2005(t=56)$ (remember that newborns start their life with zero assets).

Table IV documents these numbers for type 1 for the U.S., differentiated by their productivity shock $\eta$. The results for type 2 are nearly identical. ${ }^{10}$

\begin{tabular}{|c|c|}
\hline \multicolumn{2}{|c|}{ Table IV: Welfare Cons., US } \\
\hline Productivity $\eta_{1}$ & Productivity $\eta_{2}$ \\
\hline $0.9 \%$ & $0.6 \%$ \\
\hline
\end{tabular}

We make several observations. First, newborn agents experience welfare gains from changing factor prices and transfers induced by the demographic transition. Apart from changing preferences through higher longevity (an effect we control for in our welfare calculations) the demographic transition substantially increases the real wage over time, reduces the interest rate and first increases and then (after 2040) somewhat reduces transfers from accidental bequests. The effect from changes in transfers is small, at least for newborns. The dominating effect for newborn agents is the substantial increase in wages, partially because these agents have not yet accumulated assets and thus do not suffer from a loss of capital income on already accumulated financial wealth, in contrast to older households. Of course, a lower interest rate makes it harder for these households to accumulate assets for retirement. Since borrowing is ruled out the decline in interest rates alone therefore has unambiguously negative consequences for welfare.

Second, agents born with low productivity experience somewhat higher welfare gains than agents that start their working life with high productivity. Low productivity agents expect higher productivity in the future, and thus benefit more strongly from the increasing wage profile induced by the demographic

${ }^{9}$ For the Cobb-Douglas utility specification for $\sigma \neq 1$ the number $g(t, i, j, k, \eta, a)$ can easily be computed as

$$
g(t, i, j, k, \eta, a)=\left[\frac{\bar{W}(t, i, j, k, \eta, a)}{\overline{\bar{W}_{2005}(t, i, j, k, \eta, a)}}\right]^{\frac{1}{\omega_{i}(1-\sigma)}} .
$$

A similar expression holds for $\sigma=1$.

${ }^{10}$ The welfare consequences are very similar for other countries and type $k_{2}$. In fact, in the benchmark model the only difference across countries and types stems from accidental bequests, which are redistributed in a lump-sum fashion and whose dynamics varies slightly across countries. Since these transfers are small in magnitude, however, so are the crosscountry and cross-type differences in welfare. 
transition than the currently highly productive, whose productivity is going to fall in expectation.

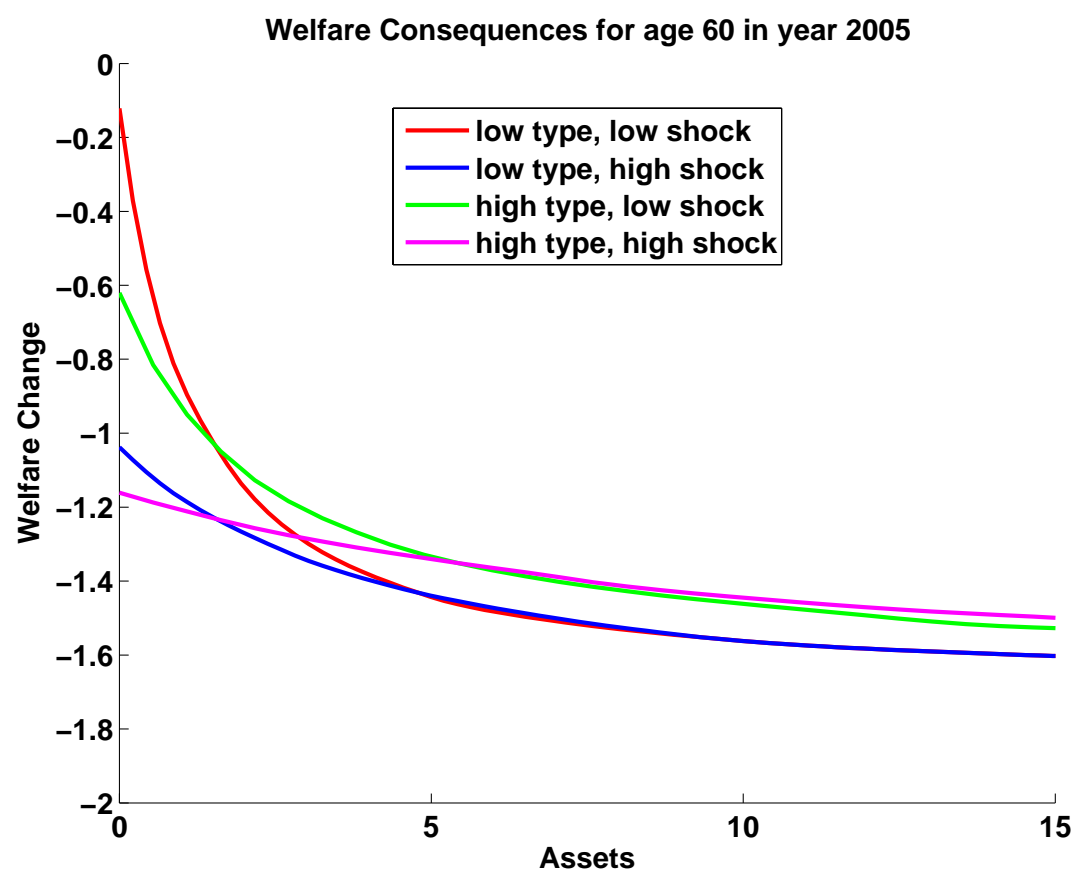

Figure 11:

Given that the welfare impact of changing factor prices constitutes a tradeoff between increasing wages and falling returns to capital one would expect that those members of society for whom labor income constitutes a smaller part of (future) resources than capital income benefit less from the demographic transition. An advantage of our model with uninsurable idiosyncratic income shocks and thus endogenous intra-cohort wealth heterogeneity is that it allows us to document how the welfare consequences are distributed across the population, both across and within cohorts. Figure 11 plots the welfare gains for agents of age 60 in 2005. These households have most of their working life behind them, thus are fairly unaffected by the wage changes, and simply experience lower returns on their accumulated savings. We see that agents in this cohort suffer welfare losses which increase substantially by the amount of financial assets they have already accumulated. To give a sense of how many agents there are at different points in the asset distribution, the support of this distribution for the 60 year old ranges roughly to $a=12$ (about 19 times GDP per capita), with median asset levels around 4 (10) times GDP per capita for the low $\eta$ - low (high) type agents and about 4.1 (10.8) times GDP per capita for the high $\eta$ low (high) type agents. Overall, a fraction of 38 percent of agents economically 
alive in 2005 gain from the changing factor prices. These tend to be young agents with little assets and currently low labor productivity.

\subsection{The Role of Social Security (and its Reform)}

So far, we completely abstracted from government policies. While it is not obvious a priori what the interaction of demographic changes and public policies is in general, it is abundantly clear from policy debates that at least one large social program is strongly affected by it: social security.

An idealized pay as you go public pension system can respond to an increase in the share of pensioners in the population by (a combination of) at least three ways: cutting benefits, increasing social security contribution rates or increasing the retirement age. While a likely response will include all elements, we now present results for the model with a PAYGO social security system that responds to population aging by either holding tax rates fixed (and thus cutting benefits), by holding replacement rates fixed (and thus raising taxes), or by increasing the retirement age. ${ }^{11}$ Because of the strong influence of a public pension system on private savings behavior, we expect that these different reform scenarios may have substantially different implications for the evolution of factor prices and the size and direction of international capital flows as well as the distribution of welfare. This conjecture turns out to be correct. Note that for all exercises we re-calibrate production and preference parameters such that each economy (with the different social security systems) attains the same calibration targets for the 1950 to 2004 period

In table $\mathrm{V}$ we show how the evolution of macroeconomic aggregates and prices differs across the various scenarios for social security. Comparing the no-social security scenario to a world with social security in which payroll tax rates are held constant (and thus benefits decline), we observe that changes in factor prices are roughly the same between the two scenarios. ${ }^{12}$ One big difference, however, is the change in social security benefits required to cope with the demographic transition, which implies a decline in replacement rates by about 8 percentage points in the scenario with social security. Column 4 demonstrates that keeping pension benefits constant and adjusting taxes, on the other hand, has dramatic consequences for the evolution of interest rates and wages, relative to the benchmark scenario of fixing tax rates for social security. With fixed benefits the incentives to save for retirement are drastically reduced, relative to the benchmark. In addition, the substantial increase in tax rates of 7 percentage points and the corresponding reduction in after tax wages makes it harder to save. Therefore, despite the decline in the fraction of households in working age (and diminished incentives to work because of higher payroll taxes) now the capital-labor ratio remains roughly unchanged, because

\footnotetext{
${ }^{11}$ In our experiment we increase the mandatory retirement age by 5 years in 2005, and keep contribution rates fixed. When needed, benefits are adjusted to retain budget balance of the social security system.

${ }^{12}$ Remember that we recalibrate our model so that in all scenarios the pre-2005 equilibrium features the same capital-output ratio.
} 
of the large reduction of household savings. Consequently the increase in wages and decline in returns is much less pronounced in this scenario. Finally, the last column of table $\mathrm{V}$ shows that an increase in the retirement age by 5 years, while leaving the change in factor prices roughly the same as in the benchmark, implies a much smaller decline in benefits as with a retirement age of 65 (see column 2). ${ }^{13}$ Because of the expansion in labor supply output per capita falls significantly less in this scenario than in all others.

\begin{tabular}{|r|r|r|r|r|}
\hline \multicolumn{6}{|c|}{ Table V. Evolution of Aggregates in US, 2005-80 } \\
\hline Var. & No Soc.Sec. & $\tau$ fixed & $\rho$ fixed & Adj of $j r$ \\
\hline$r$ & $-0.89 \%$ & $-0.86 \%$ & $-0.18 \%$ & $-0.87 \%$ \\
\hline$w$ & $4.2 \%$ & $4.1 \%$ & $0.8 \%$ & $4.0 \%$ \\
\hline$\tau$ & $0 \%$ & $0 \%$ & $7.3 \%$ & $0 \%$ \\
\hline$\rho$ & $0 \%$ & $-7.9 \%$ & $0 \%$ & $-5.0 \%$ \\
\hline$Y / N$ & $-7.6 \%$ & $-7.2 \%$ & $-12.6 \%$ & $-5.7 \%$ \\
\hline
\end{tabular}

Given these substantial differences in changes of allocations it is not surprising that the welfare consequences differ across these two scenarios as well. Table VI summarizes the welfare losses from the demographic transition for newborns in the U.S. in 2005. ${ }^{14}$ We find that, because of the decline in benefits or the increase in taxes, the welfare implications from the demographic change are less favorable in a world with social security than without. Especially the policy option of keeping benefits constant and letting tax rates increase implies large welfare losses from population aging for newborns, and even more so for future generations (not shown here). If, in contrast, the retirement age is increased to age 70, low-type households who enter the labor market unproductive are especially benefitting. These households expect productivity to be higher in the future, face increasing wages and can exploit these longer now as they can work until age 70 . It is therefore this group for which the increase in wages presents a good opportunity to inter-temporally substitute labor supply; consequently the benefit of being able to work longer and thus the overall welfare gains from changing factor prices are largest for this group. For older agents the welfare losses from the demographic transition are significantly smaller with an expansion of the retirement age, relative to simply holding contribution rates fixed and let benefits decline (results not shown). First, the decline in benefits is much smaller with an adjustment of the retirement age, and second, older households are given the option to endogenously respond to lower benefit levels by expanding their labor supply for five more years.

\footnotetext{
${ }^{13} \mathrm{~A}$ further increase in the retirement age has no substantial effect on labor supply since households are not very productive beyond age 70 and thus choose to voluntarily retire around that age.

${ }^{14}$ Note that the numbers of table VI do permit a meaningful welfare comparison of different social security reform scenarios to deal with the demographic change. In order to achieve this comparability in our welfare computations (and in these only) we always use the same parameters for all scenarios, those calibrated for the no social security benchmark.

The table does not, however, permit an assessment as to whether households are better off in a world with or without social security.
} 


\begin{tabular}{|c|c|c|c|c|c|c|c|c|}
\hline \multicolumn{7}{|c|}{ Table VI: Welfare Consequences, Newborns in U.S. } \\
\hline & No Soc.Sec. & \multicolumn{2}{c|}{$\tau$ Fixed } & \multicolumn{2}{c|}{$\rho$ Fixed } & \multicolumn{2}{c|}{ Change in $j r$} \\
\hline Type & $\eta_{1}$ & $\eta_{2}$ & $\eta_{1}$ & $\eta_{2}$ & $\eta_{1}$ & $\eta_{2}$ & $\eta_{1}$ & $\eta_{2}$ \\
\hline$k_{1}$ & $0.9 \%$ & $0.6 \%$ & $0.8 \%$ & $0.2 \%$ & $-1.6 \%$ & $-1.8 \%$ & $1.4 \%$ & $0.6 \%$ \\
\hline$k_{2}$ & $0.9 \%$ & $0.6 \%$ & $0.4 \%$ & $0.0 \%$ & $-1.8 \%$ & $-1.9 \%$ & $0.8 \%$ & $0.3 \%$ \\
\hline
\end{tabular}

Thus we conclude that the option of increasing the retirement age leads to less welfare losses (and even welfare gains for some groups) from population aging than adjusting taxes or benefits alone.

\section{Sensitivity Analysis}

In this section we discuss how our results hinge on the assumption of the U.S. being open to international capital flows from (parts of) the rest of the world, and we separately quantify the relative importance of changes in fertility and in mortality rates. Throughout these exercises, we keep social security tax rates and the retirement age constant and adjust benefits.

\subsection{The Importance of Free International Capital Flows}

Most analyses of the demographic transition and their allocative consequences are carried out in a closed economy. We therefore want to quantify the importance of international capital flows for the extent to which the return to capital in the U.S. responds to a change in its demographic structure. ${ }^{15}$ In order to do so we now show results derived under the assumption that the U.S. is a closed economy, and thus the capital stock used in its production has to be equal to total domestic asset accumulation. For an interpretation of these results it is important to keep in mind that, as figure 2 showed, the U.S. ages more slowly than the EU and the rest of the OECD. We carry out the same experiment for the rest of the OECD since that region is most rapidly aging in the 2005 to 2080 time period. ${ }^{16}$

\begin{tabular}{|r|r|r|r|r|}
\hline \multicolumn{5}{|c|}{ Table VII: Evolution of Aggregates, 2005-2080 } \\
\hline Var. & US, Open & US, Closed & ROECD, Open & ROECD, Closed \\
\hline$r$ & $-0.86 \%$ & $-0.79 \%$ & $-0.86 \%$ & $-1.03 \%$ \\
\hline$w$ & $4.1 \%$ & $3.7 \%$ & $4.1 \%$ & $5.0 \%$ \\
\hline$Y / N$ & $-7.2 \%$ & $-7.7 \%$ & $-12.6 \%$ & $-11.4 \%$ \\
\hline
\end{tabular}

\footnotetext{
${ }^{15}$ Since the rest of the world is aging at similar speed as the EU and the ROECD, repeating our exercices by letting capital flow freely also between the OECD and the rest of the world yields results that are very similar to the ones reported here.

${ }^{16}$ Not surprisingly the results for the EU lie in between those for the U.S. and those for the ROECD, given that the EU ages faster than the U.S., but slower than the ROECD.
} 
Table VII shows that the U.S. imports the more pronounced population aging from the EU and the ROECD, in the sense that it experiences a more severe decline in rates of return in the U.S. as open economy, compared to as closed economy. Evidently wages follow the reverse pattern. Output per capita falls less in the open economy because both labor input and capital used in U.S. production decline by less between 2005 and 2080 than in the closed economy. For capital, another way of stating this fact is that in the closed economy the net foreign asset position of the U.S. is constant over time (and equal to zero), whereas in the open economy it is declining over time, as more capital is flowing into the U.S. (or less savings out of it) in 2080 than in 2005. For the rest of the OECD the pattern is exactly the reverse, and the effects are somewhat more sizeable. This region, being the fastest aging in the OECD, would experience a substantially bigger fall in rates of return (and substantially larger increase in real wages) as a closed economy. Measured by the decline in the return to capital, the U.S. therefore imports some of the effects of more pronounced aging of the population in Europe and the rest of the OECD, while the ROECD exports it into the EU and especially into the U.S..

How are the welfare implications of the demographic change impacted by the degree of openness to international capital flows? Table VIII demonstrates that for the U.S. the welfare implications of population aging are hardly affected by whether it is an open or a closed economy. ${ }^{17}$ In the ROECD, on the other hand, newborns have significantly higher welfare gains in the closed, compared to the open economy, because in the former case the increase in wages is substantially stronger than in the latter. ${ }^{18}$

\begin{tabular}{|l|c|c|c|c|c|c|c|c|}
\hline \multicolumn{1}{|c|}{ Table VIII: Welfare Consequences, Newborns in U.S., ROECD } \\
\hline & \multicolumn{2}{|c|}{ US, Open } & \multicolumn{2}{c|}{ US, Closed } & \multicolumn{2}{c|}{ ROECD, Open } & \multicolumn{2}{c|}{ ROECD, Closed } \\
\hline Type & $\eta_{1}$ & $\eta_{2}$ & $\eta_{1}$ & $\eta_{2}$ & $\eta_{1}$ & $\eta_{2}$ & $\eta_{1}$ & $\eta_{2}$ \\
\hline$k_{1}$ & $0.8 \%$ & $0.2 \%$ & $0.9 \%$ & $0.3 \%$ & $0.1 \%$ & $-0.3 \%$ & $0.6 \%$ & $0.0 \%$ \\
\hline$k_{2}$ & $0.4 \%$ & $0.0 \%$ & $0.4 \%$ & $0.0 \%$ & $-0.2 \%$ & $-0.5 \%$ & $0.1 \%$ & $-0.3 \%$ \\
\hline
\end{tabular}

\subsection{Decomposing the Effects of Changes in Fertility and Mortality}

The demographic transition is caused both by changes in fertility and mortality rates. In this section we decompose our results into the part that is due to the decline in mortality rates and the part that is due to a decline in fertility rates. In order to carry out such a decomposition we have to keep in mind that in 2005 the population of our economy is not stationary, and thus changes in its

\footnotetext{
${ }^{17}$ The slighty better welfare implications for the closed economy stem from a stronger initial increase in accidental bequests, compared to the open economy, which more than offsets the lesser increase in real wages. Overall the welfare differences between the two cases are very small, however.

${ }^{18}$ However, since the decline in interest rates is much more pronounced in the closed ROECD, older generations with large amounts of accumulated assets suffer bigger welfare gains in the closed, relative to the open economy scenario in the ROCED.
} 
structure would occur even when mortality and fertility rates are held constant at their 2005 values.

In order to account for these changes we first compute the consequences from population aging assuming that mortality and fertility rates stay constant at their 2005 levels. By this, we isolate the impact of the population dynamics stemming from the nonstationary population structure in 2005. We then in addition let either mortality or fertility rates change in accordance with UN predictions and report the incremental change (over and above the pure population dynamics) induced by the change in either mortality or fertility rates. Absent strong interaction effects the changes observed in the benchmark model are then the sum of the pure population dynamics effect, the incremental effect from changes in fertility rates and the incremental effect from changes in mortality rates.

Table IX provides the outcome of this decomposition exercise and shows that the main sources of changes in factor prices and other aggregates between 2005 and 2080, at least in the U.S., come from changes in mortality rates (column 4 of table IX), and from the fact that past fertility and mortality rates have led to a population structure that would imply an aging U.S. even absent any further changes in fertility and mortality rates (column 2). In fact, since for the U.S. fertility rates (including migration rates) are predicted to increase slightly in the near future, the effect from only changing fertility rates is to make the U.S. younger (see column 3). We also observe that indeed the consequences of the demographic change can be almost perfectly be linearly dissected into to a pure composition effect, a fertility rate effect and a mortality rate effect, as columns 2-4 roughly sum to column 5 , our benchmark results documented in section 5 .

Table IX also shows that future predicted changes in fertility and mortality rates have substantially different impacts on interest rates $r$ and savings rates $s r$. The strong decline in mortality rates alone makes people live longer and thus forces them to save more, but on the other hand shifts the population towards older cohorts (which tend to be dis-savers). On net, the savings rate increases slightly. Since the fraction of the population in working age declines substantially (see the change in wapr in column 4), the capital-labor ratio increases, and with it wages; the rate of return falls as a consequence of declining mortality rates. In contrast, while an increase in fertility also increases the savings rate (since it shifts the population towards those that save, rather than dis-save), it also increases aggregate labor supply by enlarging the labor force. Thus the change in fertility rates alone reduces the capital-labor ratio and thus raises interest rates and reduces real wages. 


\begin{tabular}{|r|r|r|r|r|}
\hline \multicolumn{5}{|c|}{ Table IX: Evolution of Aggregates in the U.S., 2005-2080 } \\
\hline Var. & Only Comp. & Only $\Delta$ Fertility & Only $\Delta$ Mortality & Benchmark \\
\hline$w a p r$ & $-8.4 \%$ & $0.8 \%$ & $-4.2 \%$ & $-12.2 \%$ \\
\hline$s r$ & $-3.1 \%$ & $0.7 \%$ & $0.2 \%$ & $-2.5 \%$ \\
\hline$r$ & $-0.45 \%$ & $0.18 \%$ & $-0.66 \%$ & $-0.86 \%$ \\
\hline$w$ & $2.0 \%$ & $-0.8 \%$ & $2.8 \%$ & $4.1 \%$ \\
\hline$\rho$ & $-6.3 \%$ & $0.4 \%$ & $-1.8 \%$ & $-7.9 \%$ \\
\hline$Y / N$ & $-6.0 \%$ & $-0.3 \%$ & $-0.7 \%$ & $-7.2 \%$ \\
\hline
\end{tabular}

Overall, while predicted future changes in fertility rates are small and thus do not affect aggregates between 2005 and 2080 substantially, the large decline in mortality rates predicted for the near future explains a substantial part of the increase in wages and the reduction of real interest rates, and thus, not surprisingly, a substantial part of the welfare consequences from population aging documented above.

\section{Conclusions}

In all major industrialized countries the population is aging, bringing with it a potentially large impact on the returns to the production factors capital and labor. This paper documents that the welfare consequences from the increase in wages and declines in rates of return can be substantial, in the order of up to $1 \%$ in lifetime consumption for newborns in 2005. These welfare gains for newborns however only come along if social security contribution rates are held constant at current levels. Households that have already accumulated assets, on the other hand, lose from the decline in rates of return. Increasing the mandatory retirement age by five years is shown to substantially mitigate these losses and to significantly increase welfare gains of newborns.

The welfare gains for newborns (and losses for older generations) we document have to be added to (or traded off against) the potential welfare gains from a longer (and healthier) life that is part of the source of the aging of the population in industrialized countries. While quantifying these welfare gains is beyond the scope of the current paper, our results indicate that overall living longer is likely to be a good thing for most households, at least if social security tax rates are not increased to keep benefits constant at current levels.

Another potentially beneficial side effect of a shrinking population (or a less rapidly growing population) that we have abstracted from and that may further enhance these welfare gains emanates from a reduction in the price of housing, assuming a supply that is at least somewhat inelastic. Since a serious quantitative evaluation of this effect requires an appropriate model of housing (choice) and thus the need of adding a continuous state variable to our model, carrying out such an analysis is beyond the scope of current computational feasibility.

Finally, one important channel of adjustment to a shrinking labor force that we have abstracted from is endogenous human capital accumulation. Higher 
returns to human capital in the form of higher wages may make it optimal for young (and possibly older) households to obtain a better education, increasing the supply of effective labor. This effect may counteract some of the increase in the capital-labor ratio and hence mitigate the impact of population aging on factor prices. A quantitative exploration of this channel in a world with an aging population is left for future research.

\section{References}

[1] Abel, A. (2003), "The Effects of a Baby Boom on Stock Prices and Capital Accumulation in the Presence of Social Security," Econometrica, 71, 551-578.

[2] Altig, D., A. Auerbach, L. Kotlikoff, K. Smetters and J. Walliser (2001), "Simulating Fundamental Tax Reform in the U.S.," American Economic Review, 91, 574-595.

[3] Attanasio, O., S. Kitao and G. Violante (2006a), "Quantifying the Effects of the Demographic Transition in Developing Economies," Advances in Macroeconomics, 2, Article 2.

[4] Attanasio, O., S. Kitao and G. Violante (2006b), "Global Demographic Trends and Social Security Reform," mimeo, New York University.

[5] Auerbach, A. and L. Kotlikoff (1987), Dynamic Fiscal Policy, Cambridge University Press, Cambridge.

[6] Bloom, D. and J. Williamson (1998), "Demographic Transitions and Economic Miracles in Emerging Asia," World Bank Economic Review, $12(3), 419-455$.

[7] Börsch-Supan, A, A. Ludwig and J. Winter (2006), "Aging, Pension Reform, and Capital Flows: A Multi-Country Simulation Model," forthcoming, Economica.

[8] Brooks, R. (2003), "Population Aging and Global Capital Flows in a Parallel Universe," IMF Staff Papers, 50, 200-221.

[9] Carroll, C. (2005), "The Methods of Endogenous Gridpoints for Solving Dynamic Stochastic Optimization Problems," CFS Working Paper $2005 / 18$.

[10] Conesa, J. and D. Krueger (1999), "Social Security Reform with Heterogeneous Agents," Review of Economic Dynamics, 2, 757-795.

[11] Conesa, J. and D. Krueger (2005), "On the Optimal Progressivity of the Income Tax Code," forthcoming, Journal of Monetary Economics.

[12] Deaton, A. (1991), "Saving and Liquidity Constraints," Econometrica, 59, 1221-1248.

[13] De Nardi, M., S. İmrohoroğlu and T. Sargent (1999), "Projected U.S. demographics and Social Security," Review of Economic Dynamics, 2, 575615. 
[14] Diamond, P. (1965), "National Debt in a Neoclassical Growth Model," American Economic Review, 55, 1126-1150.

[15] Domeij, D. and M. Floden (2005), "Population Aging and International Capital Flows," forthcoming, International Economic Review.

[16] Fehr, H., S. Jokisch and L. Kotlikoff (2005), "The Developed World's demographic Transition - The Role of Capital Flows, Immigration and Policy," in R. Brooks and A. Razin (eds.) Social Security Reform Financial and Political Issues in International Perspective, Cambridge University Press, Cambridge.

[17] Feroli, M. (2003), "Capital Flows Among the G-7 Nations: A Demographic Perspective," mimeo, Federal Reserve Board

[18] Hansen, G. (1993), "The Cyclical and Secular Behavior of the Labor Input: Comparing Efficiency Units and Hours Worked," Journal of Applied Econometrics, 8, 71-80.

[19] Hendriksen, E. (2002), "A Demographic Explanation of U.S. and Japanese Current Account Behavior," mimeo, Carnegie Mellon University.

[20] Huang, H., S. İmrohoroğlu and T. Sargent (1997), "Two Computations to Fund Social Security," Macroeconomic Dynamics, 1, 7-44.

[21] İmrohoroğlu, A., S. İmrohoroğlu and D. Joines (1995), "A Life Cycle Analysis of Social Security," Economic Theory, 6, 83-114.

[22] İmrohoroğlu, A., S. İmrohoroğlu and D. Joines (1995), "Social Security in an Overlapping Generations Economy with Land," Review of Economic Dynamics, 2, 638-665.

[23] Ludwig, A. (2005), "Moment Estimation in Auerbach-Kotlikoff Models: How Well Do They Match the Data?," mimeo, MEA, University of Mannheim.

[24] Ludwig, A. (2006), "The Gauss-Seidel-Quasi-Newton Method: A Hybrid Algorithm for Solving Dynamic Economic Models," forthcoming, Journal of Economic Dynamics and Control.

[25] Obstfeld, M. and K. Rogoff (1995), "The Intertemporal Approach to the Current Account," in G. Grossman and K. Rogoff (eds.) Handbook of International Economics, Vol. 3, Elsevier, Amsterdam.

[26] Storesletten, K., C. Telmer and A. Yaron (2004), "Consumption and Risk Sharing over the Life Cycle," Journal of Monetary Economics, 51, 609633.

[27] United Nations (2002), "World Population Prospects: The 2002 Revision," United Nations Population Division, United Nations, New York. 


\section{A Details of the Demographic Projections}

For each country $i \in\{1, \ldots, I\}$ we base our demographic data on the official demographic data and projections by the United Nations (United Nations, 2002). Starting from a given initial age-distribution of population, $N_{0, \bar{j}, i}$, in year 1950 for actual age $\bar{j} \in\{0, \ldots, 96\}$ demography in each year $t$ is given recursively by

$$
\begin{aligned}
N_{t+1, \bar{j}+1, i} & =N_{t, \bar{j}, i}\left(s_{t, \bar{j}, i}+m_{t, \bar{j}, i}\right), \quad m_{t, \bar{j}, i}=0 \text { for } \bar{j}>20 \\
N_{t+1,0, i} & =\sum_{\bar{j}=15}^{50} f_{t, \bar{j}, i} N_{t, \bar{j}, i}
\end{aligned}
$$

where $m_{t, \bar{j}, i}\left(f_{t, \bar{j}, i}\right)$ denotes time, age and country specific migration (fertility) rates. Our assumption, that migration rates are zero for ages above 20 allows us to treat newborns and immigrants in the economic model alike, compare Section 3.1 .

The United Nations provide demographic data on $N_{t, \bar{j}, i}, s_{t, \bar{j}, i}$ and $f_{t, \bar{j}, i}$ on an annual basis for the years 1950-2050, but for age-groups of five only. We interpolate the initial distribution of the population, $N_{1950, \bar{j}, i}$, and the data on $s_{t, \bar{j}, i}$ and $f_{t, \bar{j}, i}$ for all $t \in\{1950, \ldots, 2050\}$ between age-groups to get agespecific data. As for migration we use the UN data on aggregate migration, $M_{t, i}$, and assume that migration numbers are equally distributed across ages for $\bar{j} \in\{0, \ldots, 20\}$. These approximations result in a decent fit of our demographic model to the official aggregate UN figures.

We further forecast demography beyond the UN forecasting horizon until 2300. First, while holding fertility rates constant, we assume that lifeexpectancy continues to increase at constant rates until year 2100. We then hold age-specific survival rates constant and assume that fertility rates adjust such that the number of newborns is constant in each successive year until 2200. This adjustment procedure implies that stationary population numbers are reached in year 2200. To support the steady state in our economic model, we hold demography constant for an additional 100 years until 2300 .

\section{B Computational Details}

\section{B.1 Household Problem}

The idea is to iterate on the Euler equation, using ideas developed in Carroll (2005). The dynamic programming problem of the household reads as

$$
\begin{aligned}
& W(t, j, k, i, \eta, a) \\
= & \max _{c, a^{\prime}, 1-l}\left\{u(c, 1-l)+\beta s_{t, j, i} \sum_{\eta^{\prime}} \pi\left(\eta^{\prime} \mid \eta\right) W\left(t+1, j+1, k, i, \eta^{\prime}, a^{\prime}\right)\right\} \\
& \text { s.t. } c+a^{\prime}= \begin{cases}\left(1-\tau_{t, i}\right) w_{t, i} \theta_{k} \varepsilon_{j} \eta l+\left(1+r_{t}\right)\left(a+h_{t, i}\right) & \text { for } j<j r \\
b_{t, j, k, i}+\left(1+r_{t}\right)\left(a+h_{t, i}\right) & \text { for } j \geq j r\end{cases} \\
a^{\prime}, c \geq 0 \text { and } l \in[0,1] &
\end{aligned}
$$


where $t$ indexes time, $j$ indexes age, $k$ indexes type, $i$ indexes country, $\eta$ denotes the idiosyncratic income shock and $a$ denotes asset holdings.

Following Deaton (1991), we denote by $x$ "cash-on-hand" as the amount of resources available if $l=1$,

$$
x= \begin{cases}\left(1-\tau_{t, i}\right) w_{t, i} \theta_{k} \varepsilon_{j} \eta+\left(1+r_{t}\right)\left(a+h_{t, i}\right) & \text { for } j<j r \\ b_{t, j, k, i}+\left(1+r_{t}\right)\left(a+h_{t, i}\right) & \text { for } j \geq j r\end{cases}
$$

Now, rewrite the Bellman equation as

$$
\begin{aligned}
& V(t, j, k,, i \eta, x) \\
= & \max _{c, 1-l}\left\{u(c, 1-l)+\beta s_{t, j, i} .\right. \\
& \left.\sum_{\eta^{\prime}} \pi\left(\eta^{\prime} \mid \eta\right) V\left(t+1, j+1, k, i, \eta^{\prime},\left(1+r_{t+1}\right)(x-e)+y^{\prime}\right)\right\},
\end{aligned}
$$

where

$$
e= \begin{cases}c+w_{t, i}\left(1-\tau_{t, i}\right) \theta_{k} \varepsilon_{j} \eta(1-l) & \text { for } j<j r \\ c & \text { for } j \geq j r\end{cases}
$$

and

$$
y^{\prime}= \begin{cases}w_{t+1, i}\left(1-\tau_{t+1, i}\right) \theta_{k} \varepsilon_{j+1} \eta^{\prime}+\left(1+r_{t+1}\right) h_{t+1, i} & \text { for } j<j r \\ b_{t+1, j+1, k, i}+\left(1+r_{t+1}\right) h_{t+1, i} & \text { for } j \geq j r\end{cases}
$$

The resulting inter-temporal Euler equation for consumption reads as

$$
\begin{aligned}
u_{c} & \geq \beta s_{t, j, i}\left(1+r_{t+1}\right) \sum_{\eta^{\prime}} \pi\left(\eta^{\prime} \mid \eta\right) V_{x^{\prime}}\left(t+1, j+1, k, i, \eta^{\prime}, x^{\prime}\right) \\
& =\text { if } a^{\prime}>0
\end{aligned}
$$

and the inter-temporal Euler equation for leisure as

$$
\begin{aligned}
u_{1-l} & \geq \beta s_{t, j, i}\left(1+r_{t+1}\right) \sum_{\eta^{\prime}} \pi\left(\eta^{\prime} \mid \eta\right) V_{x^{\prime}}\left(t+1, j+1, k, i, \eta^{\prime}, x^{\prime}\right) w_{t, i}\left(1-\tau_{t, i}\right) \theta_{k} \varepsilon_{j} \eta \\
& =\text { if } l>0
\end{aligned}
$$

and the envelope condition reads as

$$
V_{x}(t, j, k, i, \eta, x)=u^{\prime}(c)
$$

We can therefore define the intra-temporal Euler equation between consumption and leisure as

$$
\begin{aligned}
u_{1-l} & \geq u_{c} w_{t, i}\left(1-\tau_{t, i}\right) \theta_{k} \varepsilon_{j} \eta \\
& =\text { if } l>0 \text { and } a^{\prime}>0
\end{aligned}
$$


from which, for the family of Cobb-Douglas utility functions, we can get an explicit solution for leisure in terms of consumption and wages as

$$
\begin{aligned}
1-l & =1-l\left(c, w_{t, i}\left(1-\tau_{t, i}\right) \theta_{k} \varepsilon_{j} \eta\right) \\
& \text { if } \quad l>0 \text { and } a^{\prime}>0
\end{aligned}
$$

Our algorithm operates on (20), (22) and (24).

1. Define a type-independent grid for savings

$$
\mathcal{G}^{A}=\left\{0, a_{2}, \ldots, a_{n a}\right\}
$$

2. Define a type-dependent grid on $x$ for the last generation

$$
\mathcal{G}_{J, k}^{S}=\left\{x_{1, k}, x_{1, k}, \ldots, x_{n x, k}\right\}
$$

While $\mathcal{G}_{J, k}^{S}$ is type dependent we drop the dependence on $k$ from here on to simplify notation. Choose $x_{n x}>a_{n a}$ as the maximum possible realization of cash on hand and $x_{1}=x_{\min }>0$ as the minimum possible realization of cash on hand. Furthermore let $n x=n a+1$.

3. From economic theory it follows that

$$
\begin{aligned}
c(t, J, k, i, \eta, x) & =x \\
l(t, J, k, i, \eta, x) & =0 \\
a^{\prime}(t, J, k, i, \eta, x) & =0
\end{aligned}
$$

for all $x \in \mathcal{G}_{J, k}^{S}$. From $(22)$

$$
\begin{aligned}
V_{x^{\prime}}^{\prime}(t, J, k, i, \eta, x) & =u_{c}^{\prime}(t, J, k, i, \eta, x) \\
V_{x}(t, J, k, i, \eta, x) & =u_{c}(t, J, k, i, \eta, x) .
\end{aligned}
$$

4. Now iterate on $j, j=n j-1, \ldots, 1$. Given that the function $V_{x^{\prime}}^{\prime}(t+1, j+$ $1, k, i, \eta, x)$ is known from the previous step, do the following

(a) For all $a^{\prime} \in \mathcal{G}^{A}$, solve equation (20) for $c$ using equation (24) for numbers $\left(c_{1}, \ldots, c_{n a}\right)$. Since

$$
x^{\prime} \notin \mathcal{G}_{j+1, k}^{S}
$$

in general, this involves interpolation of the function $V$. For reasons of accuracy, we follow the suggestions of Carroll (2005) and interpolate on an appropriate transform of $V^{\prime}$ which is approximately linear.

(b) Equipped with the consumption numbers, calculate leisure by solving equation (24) for $\left(l_{1}, \ldots, l_{n a}\right)$.. If $l<0$ then go back to (a) and calculate consumption for $l=0$. 
(c) Equipped with the consumption and leisure numbers, define the grid $\mathcal{G}_{j, k}^{S}$ by

$$
\begin{aligned}
x_{1}= & x_{\min } \\
x_{p+1}= & \begin{cases}a_{p}+c_{p}+\left(1-l_{p}\right) w_{t, i}\left(1-\tau_{t, i}\right) \theta_{k} \varepsilon_{j} \eta & \text { for } j<j r \\
a_{p}+c_{p}+b_{t, j, k, i} & \text { for } j<j r\end{cases} \\
& \text { for } p=1, \ldots, \text { na. }
\end{aligned}
$$

In general, $x_{1}=x_{\min }$ where $x_{\min }$ is the lowest possible realization of cash on hand. If, however, $x_{\min }>x_{2}$ then replace $x_{1}$ with any number smaller than $x_{2}$.

Calculate the consumption functions

$$
\begin{aligned}
c\left(t, j, k, i, \eta, x_{1}\right) & =x_{1} \\
c\left(t, j, k, i, \eta, x_{p}\right) & =c_{p} \text { for } p=2, \ldots, n x \\
l\left(t, j, k, i, \eta, x_{p}\right) & =l_{p} \text { for } p=1, \ldots, n x \\
a\left(t, j, k, i, \eta, x_{1}\right) & =0 \\
a^{\prime}\left(t, j, k, i, \eta, x_{p+1}\right) & =a_{p} \text { for } p=1, \ldots, n a
\end{aligned}
$$

(d) Update for all $x \in \mathcal{G}_{j, k}^{S}$

$$
\begin{aligned}
& V_{x}(t, j, k, i, \eta, x) \\
= & u_{c}(c(t, j, k, i, \eta, x), 1-l(t, j, k, i, \eta, x)) \\
& V(t, j, k, i, \eta, x) \\
= & u(c(t, j, k, i, \eta, x), 1-l(t, j, k, i, \eta, x))+\beta s_{t, j, i} \\
& \sum_{\eta^{\prime}} \pi\left(\eta^{\prime} \mid \eta\right) V\left(t+1, j+1, k, i, \eta^{\prime}, x^{\prime}\right)
\end{aligned}
$$

The updating of the value function again involves interpolation.

\section{B.2 The Aggregate Model}

For a given $r \times 1$ vector $\vec{\Psi}$ of structural model parameters, we first solve for an "artificial" initial steady state in period $t=0$ which gives an initial distribution of assets. We thereby presume that households assume prices to remain constant for all periods $t \in\{0, \ldots, T\}$ and are then surprised by the actual price changes induced by the transitional dynamics. Next, we solve for the final steady state of our model which is reached in period $T$ and supported by our demographic projections, see appendix A. For both steady states, we solve for the equilibrium of the aggregate model by iterating on the $m \times 1$ steady state price vector $\vec{P}_{s s}=$ $\left[p_{1}, \ldots, p_{m}\right]^{\prime} . p_{1}$ is the world marginal product of capital, $r_{t}+\delta, p_{2}, \ldots, p_{I+1}$ are social security contribution (or replacement) rates of each country, $\tau_{t, i}\left(\rho_{t, i}\right)$, and $p_{I+2}, \ldots, p_{2 I+1}$ are accidental bequests (as a ratio of wages) in each country, 
$\frac{h_{t, i}}{w_{t, i}}$. Notice that all elements of $\vec{P}_{s s}$ are defined such that they are constant in the steady states.

Solution for the steady states of the model involves the following steps:

1. In iteration $q$ for guess $\vec{P}_{s s}^{q}$ solve the household problem.

2. Next aggregate across all households in all countries to get the worldwide aggregate capital stock, $\sum_{i} K_{t, i}$. Define by $\kappa_{t, i}$ the capital stock per efficiency unit in country $i$,

$$
\kappa_{t, i}=\frac{K_{t, i}}{Z_{i}^{1 /(1-\alpha)} A_{t} L_{t, i}}=\kappa_{t} \forall i
$$

which is constant across all countries by our assumption of perfect capital mobility and the market market clearing condition for the world interest rate, $r_{t}+\delta=\alpha \kappa_{t}^{\alpha-1}$. It follows that

$$
\sum_{i} K_{t, i}=\kappa_{t} \sum_{i} Z_{i}^{1 /(1-\alpha)} A_{t} L_{t, i}
$$

We use this condition to form an update of the world marginal product of capital, $\tilde{p}_{1}$.

3. Aggregate across all households to get aggregate labor supply in each country, $L_{t, i}$. Update social security contributions (or replacement rates) using the social security budget constraint, equation (16). Calculate bequests in each country by equation (18).

4. Collect the updated variables in $\tilde{\vec{P}}_{s s}$ and notice that $\tilde{\vec{P}}_{s s}=H\left(\vec{P}_{s s}\right)$, where $H$ is a vector-valued non-linear function.

5. Define the root-finding problem $G\left(\vec{P}_{s s}\right)=\vec{P}_{s s}-H\left(\vec{P}_{s s}\right)$, where $G$ is a vector-valued non-linear function, and iterate on $\vec{P}_{s s}$ until convergence. We use Broyden's method to solve the problem and denote the final approximate Jacobi matrix by $B_{s s}$.

Next, we solve for the transitional dynamics by the following steps:

1. Use the steady state solutions to form a linear interpolation to get the starting values for the $m(T-2) \times 1$ vector of equilibrium prices, $\vec{P}=$ $\left[\vec{p}_{1}^{\prime}, \ldots, \vec{p}_{m}^{\prime}\right]^{\prime}$, where $p_{i}, i=1, \ldots, m$ are vectors of length $(T-2) \times 1$.

2. In iteration $q$ for guess $\vec{P}^{q}$ solve the household problem. We do so by iterating backwards in time for $t=T-1, \ldots, 2$ to get the decision rules and forward for $t=2, \ldots, T-1$ for aggregation.

3. Update variables as in the steady state solutions and denote by $\tilde{\vec{P}}=H(\vec{P})$ the $m(T-2) \times 1$ vector of updated variables. 
4. Define the root-finding problem as $G(\vec{P})=\vec{P}-H(\vec{P})$. Since $T$ is large, this problem is substantially larger and we use the Gauss-Seidel-Quasi-Newton algorithm suggested in Ludwig (2006) to form and update guesses of an approximate Jacobi matrix of the system of $m(T-2)$ non-linear equations.

\section{B.3 Calibration of Structural Model Parameters}

Calibration of structural model parameters is based on a procedure suggested in Ludwig (2005). We split the $r \times 1$ vector of structural model parameters, $\vec{\Psi}$, as $\vec{\Psi}=\left[\left(\vec{\Psi}^{e}\right)^{\prime},\left(\vec{\Psi}^{f}\right)^{\prime}\right]^{\prime} \cdot \vec{\Psi}^{f}$ is a vector of predetermined (fixed) parameters, whereas the $e \times 1$ vector $\vec{\Psi}^{e}$ is estimated by minimum distance (unconditional matching of moments using $e$ moment conditions). Denote by

$$
u_{t}\left(\vec{\Psi}^{e}\right)=y_{t}-f\left(\vec{\Psi}^{e}\right) \text { for } t=0, \ldots, T_{0}
$$

the GMM error as the distance between data, $y_{t}$, and model simulated (predicted) values, $f\left(\vec{\Psi}^{e}\right)$.

Under the assumption that the model is correctly specified, the restrictions on the GMM error can be written as

$$
E\left[u_{t}\left(\vec{\Psi}_{0}^{e}\right)\right]=0,
$$

where $\tilde{\Psi}_{0}^{e}$ denotes the vector of true values. Denote sample averages of $u_{t}$ as

$$
g_{T_{0}}\left(\vec{\Psi}^{e}\right) \equiv \frac{1}{T_{0}+1} \sum_{t=0}^{T_{0}} u_{t}\left(\vec{\Psi}^{e}\right)
$$

We estimate the elements of $\vec{\Psi}^{e}$ by setting these sample averages to zero (up to some tolerance level).

In our economic model, the vector $\vec{\Psi}^{e}$ is given by

$$
\vec{\Psi}^{e}=\left[g, \delta, \alpha, Z_{i}, \ldots, Z_{I}, \beta, \omega_{i}, \ldots, \omega_{I}\right]^{\prime} .
$$

We estimate the structural model parameters using data from various sources for the period $1960, \ldots, 2004$, hence $T_{0}=44$. To identify the parameters of the production function, $g, \delta$, $\alpha$, we use NIPA data for the U.S. on GDP, fixed assets, depreciation, wages and labor supply. Since our economic model restricts the capital-output ratio to be equal across countries, we restrict $Z_{1}=1$ and estimate $Z_{i}$ for $i>1$ using data on labor productivity of country $i$ relative to the U.S.. The remaining structural model parameters, $\beta, \omega_{1}, \omega_{2}, \omega_{3}$ are estimated by simulation. We estimate $\beta$ by setting to zero the average distance between the simulated and the actual capital-output ratio and $\omega_{1}, \omega_{2}, \omega_{3}$ by setting to zero the average distance between simulated and actual average hours worked. The predetermined parameter of our model is the coefficient of relative risk aversion, $\sigma$, which we set to one. In addition, we impose the restriction that the parameters, $\alpha, \delta, g, \beta, \sigma$, are constant across countries. 